\title{
Preliminary results of the comparison of ATSR measurements with in situ sea temperatures.
}

\author{
ATSR Science Team Meeting: Validation results. \\ Cosener's House Conference Centre, Abingdon, U.K. \\ March 30, 1993.
}

\author{
P.J. Minnett \\ Oceanographic and Atmospheric Sciences Division \\ Brookhaven National Laboratory \\ Upton, New York 11973
}

tel. (516) 2825983

March 17, 1993

fax. (516) 2823246

OMNET P.MINNETT

email minnett@bnl.gov

\section{DISCLAIMER}

\begin{abstract}
This report was prepared as an account of work sponsored by an agency of the United States Government. Neither the United States Government nor any agency thereof, nor any of their employees, makes any warranty, express or implied, or assumes any legal liability or responsibility for the accuracy, completeness, or usefulness of any information, apparatus, product, or process disclosed, or represents that its use would not infringe privately owned rights. Reference herein to any specific commercial product, process, or service by trade name, trademark, manufacturer, or otherwise does not necessarily constitute or imply its endorsement, recommendation, or favoring by the United States Government or any agency thereof. The views and opinions of authors expressed herein do not necessarily state or reflect those of the United States Government or any agency the reof.
\end{abstract}

This research was performed under the auspices of the United States Department of Energy under Contract No. DE-AC02-76CH00016.

By acceptance of this article, the publisher and/or recipient acknowledges the U.S. Government's right to retain a nonexclusive, royalty-free license in and to any copyright covering this paper. 
During October and November, 1991, the NATO Research Vessel Alliance sailed from Amsterdam into the western Mediterranean Sea and during this time measurements were made for the validation of ATSR data. This document reports the initial comparison between ATSR measurements and sea-surface temperatures (SSTs) taken along the ship's track by an in situ thermometer at a depth of about $3 \mathrm{~m}$.

\section{Itinerary}

The ship sailed from Amsterdam at about mid-day on October 1. The route from Holland was through the English Channel, across the Bay of Biscay, southward to the west of Portugal, through the Strait of Gibraltar, and across the Western Mediterranean to La Spezia. The ship was in the port at La Spezia from the 9 to 15 October, 18 October, and 21 to 24 October to change over other scientists and equipment between cruises. The two short cruises on 16-17 October, and 19-20 October were in waters near to La Spezia, while the final cruise from 25 October to 9 November was divided between the Corsican Sea to the south of the Island of Elba, and the western Mediterranean Sea to the west of Sardinia.

The track of the ship for the period 1 October to 9 November is shown in Fig. 1.

\section{Ship-Board Instrumentation}

For very nearly all of the period at sea high quality measurements of sea-surface temperature, surface meteorological variables and surface infrared radiances were taken by a set of instruments mounted on the ship and logged by computers. The ship is equipped with a set of meteorological sensors (including SST thermometers) and a precision infrared SST radiometer and these were augmented by a sky radiometer and a radiosonde station for this cruise.

The surface temperatures used here are from the Sea-Bird CTD which was mounted through the hull so that it extended beyond the ship's boundary layer, at a depth of about $3 \mathrm{~m}$. It is acknowledged that these data are not ideal for the validation of ATSR as they may be decoupled from the true surface temperature by the skin effect and possible diurnal thermoclines, but at the time of writing they provide the temperatures in which I have most confidence. One minute averages of 1 -second samples are used. At present, the data from the ship radiometer (R.A.L./S.I.L. type) are not ready for use, although it is anticipated that these will form the basis of a validation of ATSR using skin temperatures.

Atmospheric profiles of temperature and humidity were made using disposable radiosondes carried aloft by helium balloons. The measurements are transmitted to a receiving station (an AIR Inc. Atmospheric Data Acquisition System - ADAS) on the ship. The radiosondes were launched, when possible, so their ascents coincided with satellite overpasses 
when the sky was reasonably clear of cloud, thereby increasing the chances of good satellite data.

Values of latitude, longitude, ship's speed, heading (gyrocompass reading) and course made good derived by the ship's Precision Location and Navigation System were archived at intervals of about one minute.

\section{ATSR on the ERS-1}

ERS-1 is a polar-orbiting earth-observation satellite carrying a range of instruments designed for studying the ocean-ice-climate system. The spacecraft is in a sun-synchronous, circular orbit at an altitude of about $785 \mathrm{~km}$ with an inclination of about $97.5^{\circ}$ and a nodal period of about $100 \mathrm{~min}$. The local solar time of the descending node is about 10:45.

The ATSR/M is a scarning four-channel infrared radiometer incorporating a two channel nadir-pointing microwave radiometer and is the first satellite instrument to have been designed for the accurate measurement of sea-surface temperature. It uses the same infrared channels as the AVHRR (Advanced Very High Resolution Radiometer on the NOAA series of polar-orbiting satellites), but has a novel approach to the correction of the effects of the intervening atmosphere, in that the same $500 \mathrm{~km}$ swath of the ocean surface is measured twice through different atmospheric path lengths. This information, coupled with the multichannel measurements, permits an improved atmospheric correction. In addition, improved internal black-body calibration targets enable a more accurate in-flight calibration, and detectors refrigerated to liquid nitrogen temperatures improve the signal to noise level.

\section{ATSR data.}

Four scenes of level 1.5 (brightness temperature) data and level 2 (derived SST images) were provided by RAL from the period of this cruise. They are listed in Table 1 . Of these, one (PK30\$110282125_4430_20423_310.BT;1) is severely contaminated by cloud and for another (PK30\$110072126_4130_20423_310.BT;1) the ship track only cuts across a comer of the image. For the remaining two the ship's track transects the scenes (Figures 2 and 8). Clouds were present in both scenes, but the positions of the ship at the time of the satellite overpasses were under clear skies. Note that the time taken for the ship to complete the trank across the image is nearly one day and comparisons must be restricted to that part of the ship's irack close to the ship's position at the time of the satellite overpass.

\subsection{Image navigation}

The geographic location of individual pixels was calculated by bi-linear interpolation between the $25 \mathrm{~km}$ grid provided in the image files. The accuracy of the grid was determined by overlaying the coastal outlines (extracted from the CIA coast-line data base). In both images 
significant offsets were found (Table 2). For the image of 2 October (Figure 2), the shifts to overlay precisely the coastlines were uniform across the image, but for the image of 6 October a shift which varied across the image was required (Figure 8). The shifts were different for the corresponding nadir and forward views. The simple line shifts in the direction of the satellite path are probably the result of uncertainties in the knowledge of the position of the satellite in space (or an error in the time base), whereas those in October 6 image probably result from an inadequate determination of the space-craft's attitude in space (a yaw-steering problem?).

In the presence of surface temperature gradients, the relative offsets between the forward and the nadir views could have serious consequences for SST determination. This will be discussed below.

\subsection{Atmospheric correction}

The pixels along the position of the ship's track were sampled to extract the ATSR measured brightness temperatures in the nadir and forward views at $10.8 \mu \mathrm{m}$ and $12 \mu \mathrm{m}$. Plots of these, as a function of longitude are shown together with the $-3 \mathrm{~m}$ SST in Figures 3 and 8 . SSTs were calculated from these brightness temperatures using coefficients calculated by Albin Zavody, for both the nadir swath multichannel split-window algorithm and the dual-angle multichannel algorithm. The coefficients as supplied were applicable to $50-\mathrm{km}$ wide subswaths symmetrically placed on each side of the sub-satellite track. These coefficients were used to generate values that change smoothly across the swath by a least squares fourth-order polynomial fit (Figure 4). The resulting SST traces along the ship's track are shown in Figures 5,6,10 and 11, with the $-3 \mathrm{~m}$ SST for comparison. The traces are shown with simple block-average smoothing over 9 samples in Figures 7 and 12.

SST images were calculated for each of these two scenes. In each case three estimates of the SST field were generated. The first used the nadir split-window algorithm, the second the dual-angle split-window algorithm without any attempt at correcting the relative position of the forward scan data with respect to the nadir scan data, and the third using the dual-angle splitwindow algorithm with the forward scan data shifted to overlap the nadir scan data in a more proper fashion. The SST images are shown in Figures 13 to 18.

\subsection{Atmospheric profiles}

The atmospheric profiles of temperature, humidity and precipitable water derived from radiosonde measurements close to the times of the ERS-1 overpasses are shown in Figures 19 and 20. 


\section{Discussion}

\subsection{General performance}

The brightness temperature images (e.g. Figures 2 and 8 ) are apparently free instrumental noise. The temperature features observable in the ocean appear realistic and uncontaminated by instrumental effects. This is also true of the $3.7 \mu \mathrm{m}$ image from October 6 (not shown).

\subsection{Brightness temperatures}

The traces of brightness temperatures along the ship's track appear to be entirely credible. The decreasing brightness temperatures with increasing wavelength and increasing atmospheric path length are as expected. The relative effects of the spectral brightness temperature gradient and the atmospheric path length gradient are different in the two scenes and this is presumably due to the different atmospheric conditions on the two days. On October 2, the brightness temperature difference between the $10.8 \mu \mathrm{m}$ and the $12 \mu \mathrm{m}$ nadir measurements is comparable to that between the nadir and forward measurements at $10.8 \mu \mathrm{m}$ (Figure 3). Towards the west the atmospheric conditions change and the $10.8 \mu \mathrm{m}$ measurement becomes colder than that at nadir $12 \mu \mathrm{m}$ at nadir. Towards the east, the radiosonde launched from the ship shows that the atmosphere was anomalously dry at mid levels, between 1 and $2 \mathrm{~km}$ height (Figure 19). On October 6 , the brightness temperature difference between the $10.8 \mu \mathrm{m}$ and the $12 \mu \mathrm{m}$ nadir measurements is only about half of that between the nadir and forward measurements at $10.8 \mu \mathrm{m}$ (Figure 9). The atmosphere was anomalously dry at higher levels, between 3 and $4 \mathrm{~km}$ height (Figure 20).

\subsection{SST comparison}

Comparison of ship SST and ATSR derived SST is encouraging. In the October 2 case, the split window retrieval overcompensates the effect of the atmosphere and produces an SST retrieval that is warmer than the $-3 \mathrm{~m}$ bulk measurement (Figures 5 and 7). Given that the skin temperature is expected to be lower than the bulk temperature by a few tenths of a degree, the dual-angle SST retrieval looks to be very accurate indeed (Figures 6 and 7). The discrepancy between the two ATSR SST retrievals diminishes towards the west as the atmospheric conditions change. Note that the ship measurements can not be used to validate the satellite retrieval here because of the excessive time interval between the ship and satellite measurements. The comparison on October 6 does not show a clear advantage of the dual-angle retrieval (Figures 10,11 and 12).

\subsection{Noise levels in the SST fields}

The nadir-only split-window SST images (Figures 13 and 16), and sections (Figures 5 and 10) are very clean and noise-free. The dual-angle split-window SST retrievals are significantly noisier than those derived from the nadir scans alone, even after the errors in the relative location of the forward and nadir scans have been corrected (Figures 14, 15, 17 and 18). This results from at least three effects: the SST is derived by the combination of fours channels of information instead of two, and each channel contributes some noise to the retrieval; the coefficients in the dual angle retrieval are larger than in the nadir-only retrieval (Figure 4) and these magnify the noise levels; and the mismatch in the pixel sizes in the forward and nadir 
swaths. The last effect may be the most important, and is most readily corrected, as instead of mapping the forward view pixels into the nadir swath, which requires oversampling of the forward-view information, the nadir swath pixels could be mapped into the forward view image. Although this would lead to a loss of resolution it may reduce the noise level.

\subsection{Effects of spatial averaging}

Averaging the SST traces may produce a more stable estimate of the SST (Figures 21 and 22, Table 3), but the standard deviation of the derived SSTs is consistently higher for the dual-angle retrieval compared to the split-window retrieval, by about a factor of two. For studies of oceanic variability this might be a problem.

\subsection{Effects of mislocation of forward view data}

Without correction of the dislocation between the forward and nadir scans the dual-angle retrieval suifers badly near clouds, coasts and SST fronts (Figures 14 and 17). This leads to unnecessary loss of information to cloud clearing algorithms, especially those based on local inhomogeneity tests. With the position of the forward view measurements corrected, the dualangle SST retrieval is much improved, but remains noisier than the split-window retrieval.

\subsection{Comparison of different atmospheric corrections}

To determine the differences of the retrieval algorithms in cloud-free areas, the statistics of the SSTs in distinct areas were compared. Only one region in the October 2 image was used (Figure 23), but six were used from the October 6 image. These were selected to span the width of the swath and to include areas with and without significant horizontal SST gradients. The statistics of the comparison are given in Table 4 and the histograms of the pixel values in the areas are given in Figures 25 to 31). The surprising result is that although the uncorrected dualangle SST retrieval is obviously contaminated in the areas of SST gradients, these errors are such that they do not invalidate estimated of SST on scales larger than the induced errors, i.e. the errors a sufficiently symmetrical to cancel out. This is a very fortuitous result as this areas used here were chosen to be comparable to the high accuracy 0.5 degree SST field operationally produced from the ATSR data. For spatial averages on smaller scales the result might be different, unless the errors are misidentified as resulting from cloud contamination and removed from the processing procedure. In this case statistics of cloud occurrence will be wrong.

\subsection{Effects of clouds}

The effects of clouds are more pronounced in the dual angle retrievals, even when the dislocation of the forward view measurements is corrected (Figures 15, 15, 17 and 18). This is an inevitable consequence of the parallax in the forward view measurements (Figures 3 and 9). 


\section{Conclusions}

The ATSR is performing well, and the atmospheric correction coefficients derived by Albin Zavody appear to function very well, although the sample presented here is too small to draw firm conclusions.

The errors in the geolocation of the images are large, and the dislocation of forward view measurements with respect to those from the nadir view is disconcerting. This leads to an unnecessary loss of data in the retrieved SST fields to the cloud detection algorithm, but surprisingly does not lead to a significant degradation in accuracy in the SST values averaged over $50 \times 50$ pixels, or so.

The variance of the SST in a given area is much greater when the SST field has been derived using a dual-angle atmospheric correction, even when the dislocation of the forward view measurements has been corrected, than that when using the nadir-only atmospheric correction.

More comparisons must be made to evaluate thoroughly the benefits of the dual-angle atmospheric correction technique.

\section{致}

\section{Acknowledgements.}

The support during the cruise of the ship's officers and crew and technical staff from the SACLANT Undersea Research Centre is appreciatively acknowledged. Support from the National Oceanic and Atmospheric Administration, Grant NA26GP0266-01, is acknowledged. This document was prepared under the auspices of the United States Department of Energy under Contract No. DE-AC02-76CHOOO16.

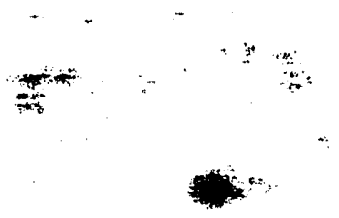


Table 1. ATSR images provided by ATSR Ground Segment Facility, Rutherford Appleton Laboratory, U.K.

File name

Date, time

Area

PK38_UK\$110021049_14230_20423_310.BT;1

2 Oct.' $91,10: 49$

6 Oct.' $91,21: 59$

7 Oct.' $91,21: 26$

28 Oct.' $91,21: 25$

English Channel

W. Mediterranean Sea

W. Mediterranean Sea

PK30\$110072126_4130_20423_310.BT; 1

PK30\$1 10282125_4430_20423_310.BT; 1

W. Mediterranean Sea

Table 2. Offsets in line and pixels to force coincidence with coastlines.

File - PK38_UK\$110021049_14230_20423_310.BT;1

Line adjustment

Nadir swath

Forward swath

File-PK16\$110062159_3930_20423_310.BT;1

Line adjustment

Nadir swath

Forward swath

- where $\mathrm{i}$ is pixel number across swath, starting with 0 at the western edge of the image.

\section{Pixel adjustment}

$+2$

$+2$
$-4$
$i^{*}(1+4 / 511)$
$-3$
$i^{*}(1+10 / 511)+3$ 
Table 3. Difference in the SSTs, corrected for the intervening atmosphere, referenced to the $3 \mathrm{~m}$ depth SST.

File - PK38_UK\$110021049_14230_20423_310.BT;1 October 2.

$\begin{array}{clll}\begin{array}{l}\text { Number of } \\ \text { samples } \\ \text { along track } \\ \text { in average }\end{array} & \begin{array}{l}\text { Bulk SST } \\ \text { 3m depth } \\ \text { mean } \pm 1 \text { s.d }\end{array} & \begin{array}{l}\text { Nadir only } \\ \text { split-window } \\ \text { mean } \pm 1 \text { s.d. }\end{array} & \begin{array}{l}\text { Dual-angle } \\ \text { split-window } \\ \text { mean } \pm 1 \text { s.d. }\end{array} \\ 1 & 290.01 & 290.23 & 289.44 \\ 3 & 290.01 \pm 0.006 & 290.27 \pm 0.11 & 289.48 \pm 0.34 \\ 5 & 290.01 \pm 0.004 & 290.29 \pm 0.11 & 289.53 \pm 0.30 \\ 7 & 290.01 \pm 0.005 & 290.28 \pm 0.09 & 289.52 \pm 0.25 \\ 9 & 290.01 \pm 0.004 & 290.30 \pm 0.11 & 289.55 \pm 0.28 \\ 11 & 290.01 \pm 0.004 & 290.34 \pm 0.12 & 289.63 \pm 0.28 \\ 21 & 290.01 \pm 0.005 & 290.34 \pm 0.15 & 289.65 \pm 0.33\end{array}$

File - PK16\$110062159_3930_20423_310.BT;1 October 6.

$\begin{array}{clll}1 & 293.48 & 292.16 & 291.72 \\ 3 & 293.48 \pm 0.000 & 292.24 \pm 0.13 & 291.87 \pm 0.26 \\ 5 & 293.48 \pm 0.004 & 292.23 \pm 0.12 & 291.90 \pm 0.25 \\ 7 & 293.48 \pm 0.004 & 292.36 \pm 0.24 & 292.10 \pm 0.43 \\ 9 & 293.48 \pm 0.004 & 292.43 \pm 0.26 & 292.21 \pm 0.46 \\ 11 & 293.48 \pm 0.004 & 292.45 \pm 0.24 & 292.29 \pm 0.47 \\ 21 & 293.48 \pm 0.005 & 292.49 \pm 0.19 & 292.39 \pm 0.42\end{array}$


Table 4. Discrepancies in SSTs with respect to the dual-angle split-window retrieval in cloud-free areas.

$\begin{array}{ccll}\text { Boundary of box } & \text { Nadir only } & \text { Dual-angle } \\ \text { pixels } & \text { lines } & \text { mean } \pm 1 \text { s.d. } & \text { mean } \pm 1 \text { s.d. }\end{array}$

File - PK38_UK\$110021049_14230_20423_310.BT;1 October 2.

$\begin{array}{llll}30: 89 & 150: 209 & 0.670 \pm 0.258 & 0.005 \pm 0.345\end{array}$

File - PK16\$110062159_3930_20423_310.BT;1 October 6.
A $10: 59$
230:279
$-0.439 \pm 0.441$
$-0.145 \pm 0.503$
B $\quad 110: 159$
$110: 159$
$-0.376 \pm 0.213$
$-0.005 \pm 0.281$
C. 260:309
$150: 199$
$-0.426 \pm 0.215$
$0.004 \pm 0.369$
D $235: 284$
245:294
$-0.545 \pm 0.276$
$-0.008 \pm 0.432$
E $\quad 370: 419$
$180: 229$
$-0.404 \pm 0.230$
$-0.001 \pm 0.329$
F $\quad 450: 499$
420:469
$-0.004 \pm 0.325$
$0.007 \pm 0.496$

1 The values are the differences between SSTs derived using the nadir-only split-window atmospheric correction and the dual-angle split-window atmospheric correction in which the mislocation of the forward-view measurements has been corrected.

2 The values are the differences between SSTs derived using the dual-angle split-window atmospheric correction without correction of mislocation of the forward-view measurements, and with the correction of the forward-view measurements. 


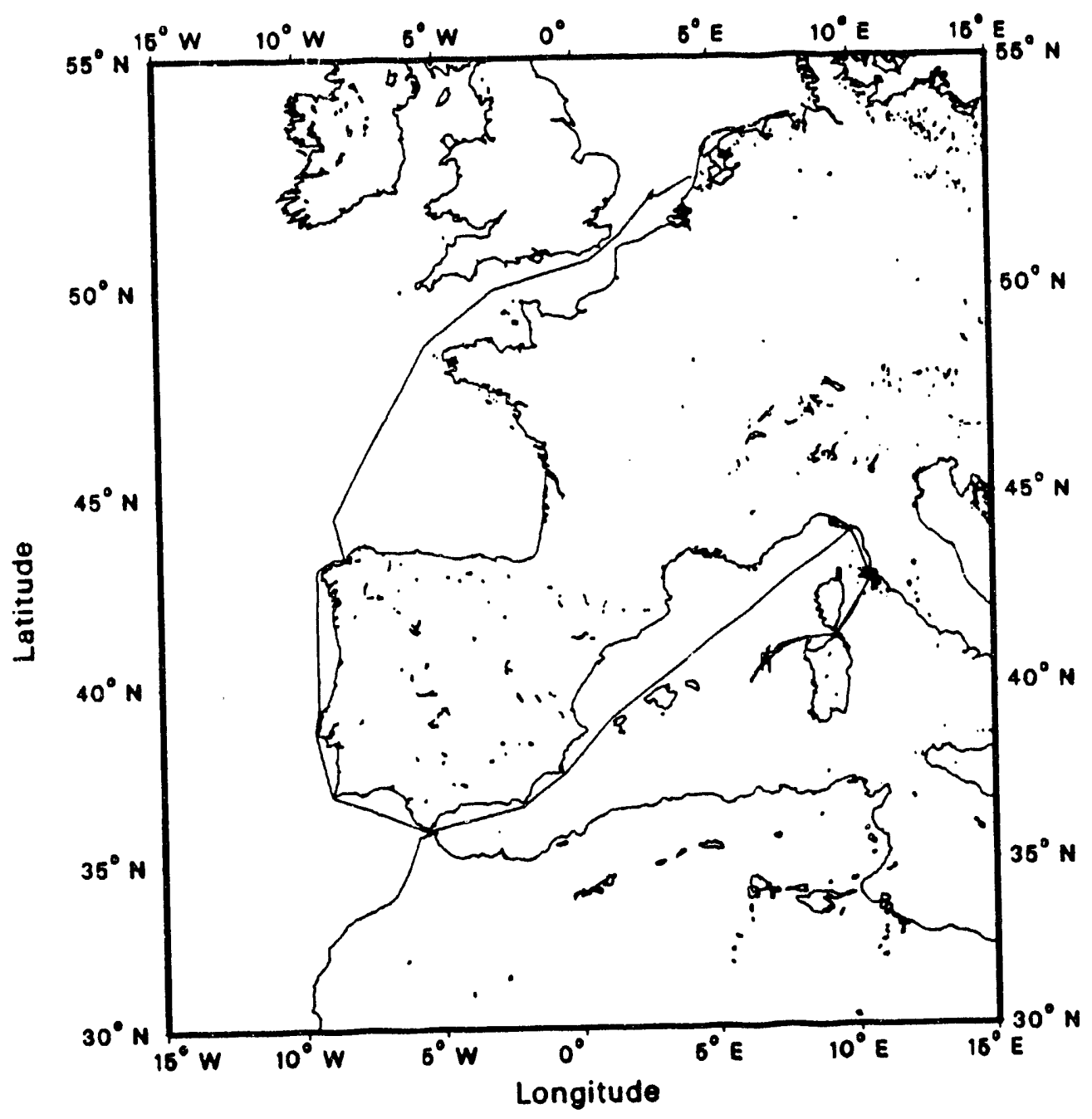

Figure 1. Track of the R/V Alliance, 1 October to 9 November, 1991. 
ERS-1 ATSR, 2 October 1991, 10:49. R/V Alliance track

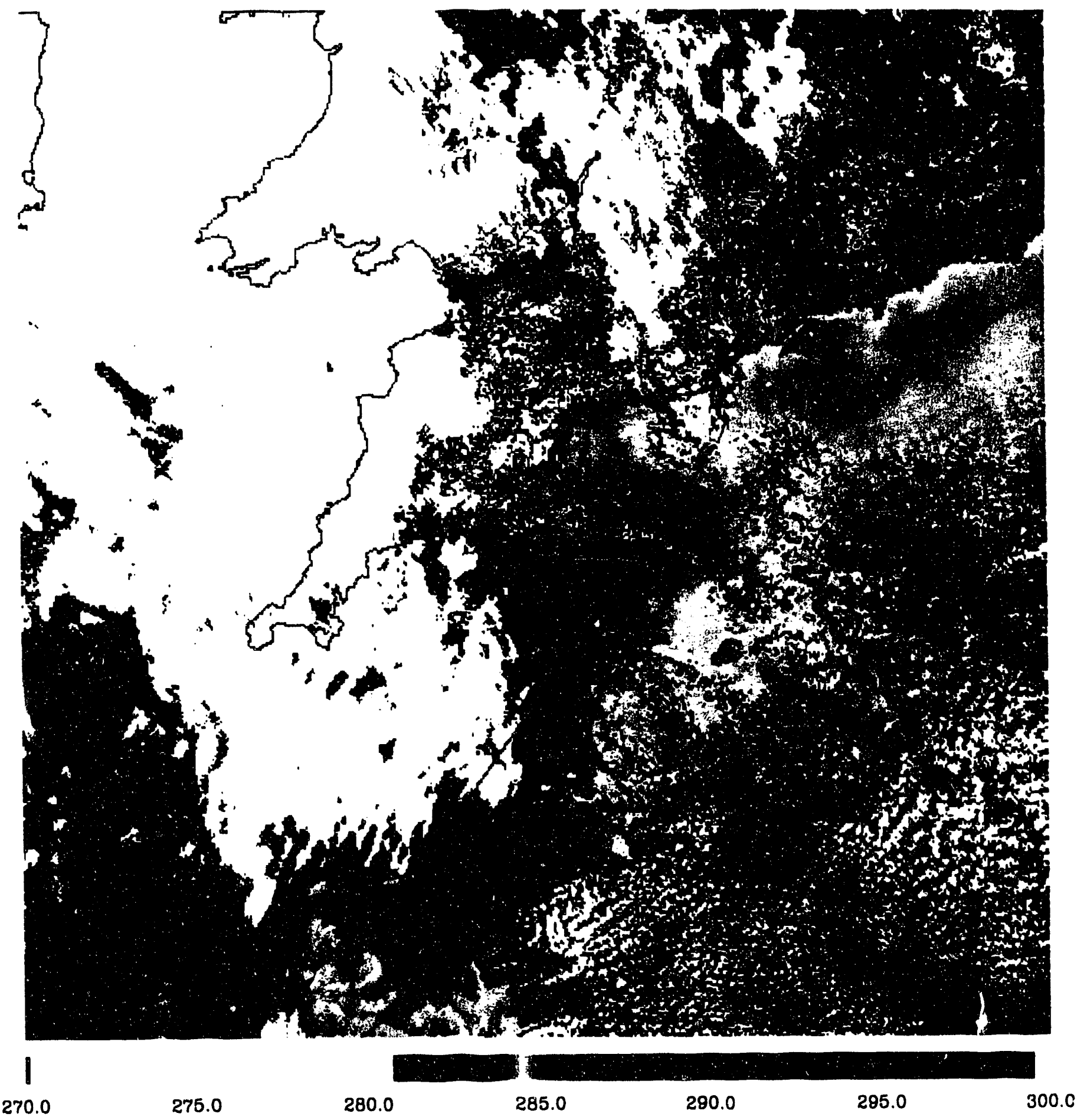

Figure 2. ATSR brightness temperature image of the 2 October overpass of the ship's track. The data were taken at 10:49 UTC and the $12 \mu \mathrm{m}$ nadir measurements are shown. The ship's track between 10:18 on October 2 to 07:33 on October 3 is shown. The positions of the coast-lines and ship's track are corrected for the errors in the image geolocation as given in Table 2 . 


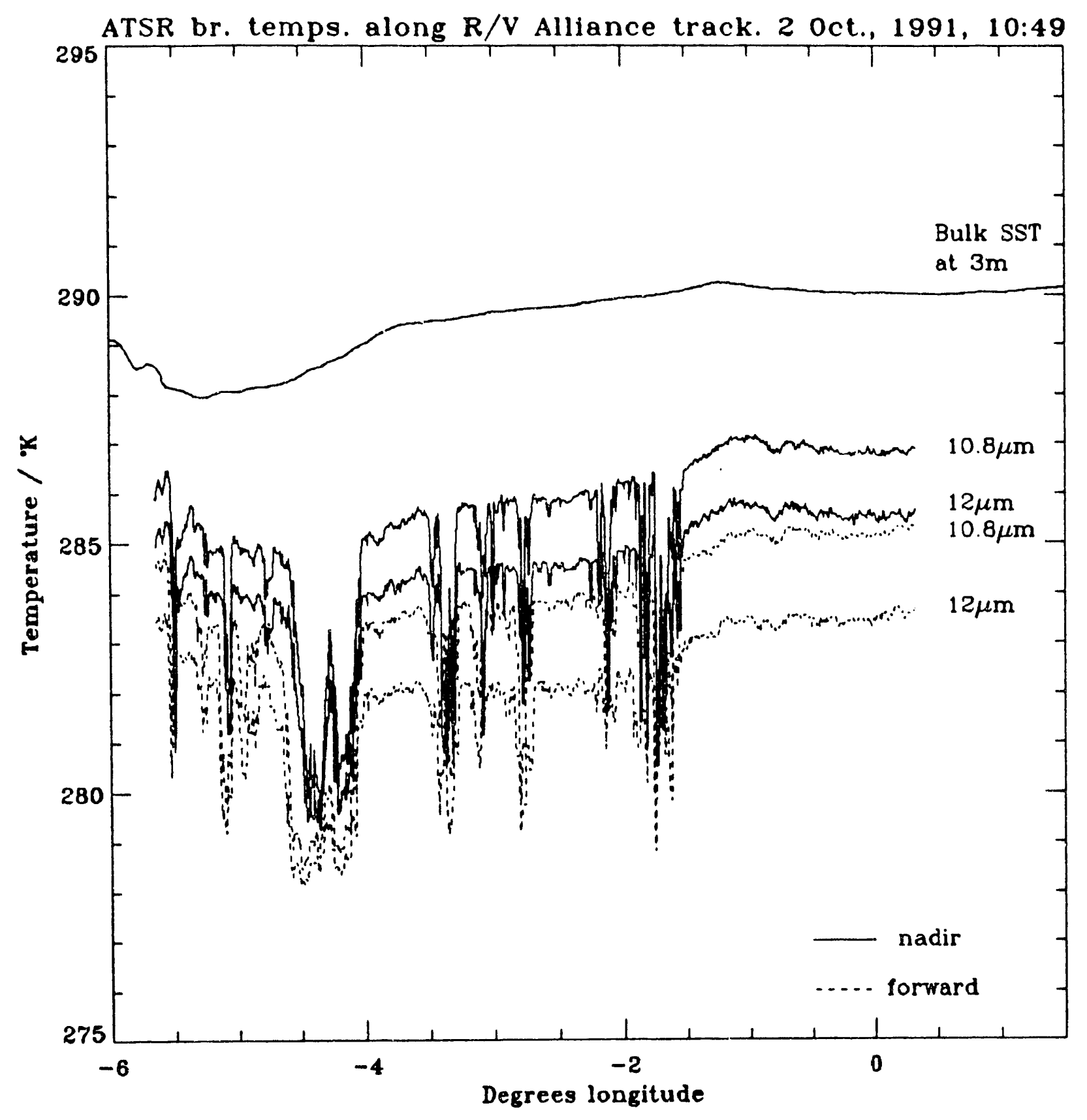

Figure 3. ATSR brightness temperature sections with the $-3 \mathrm{~m}$ in situ SST along the track of the ship for the image taken on October 2, 1991. 
ATSR Split-window SST retrieval coefficients. Mid latitude.
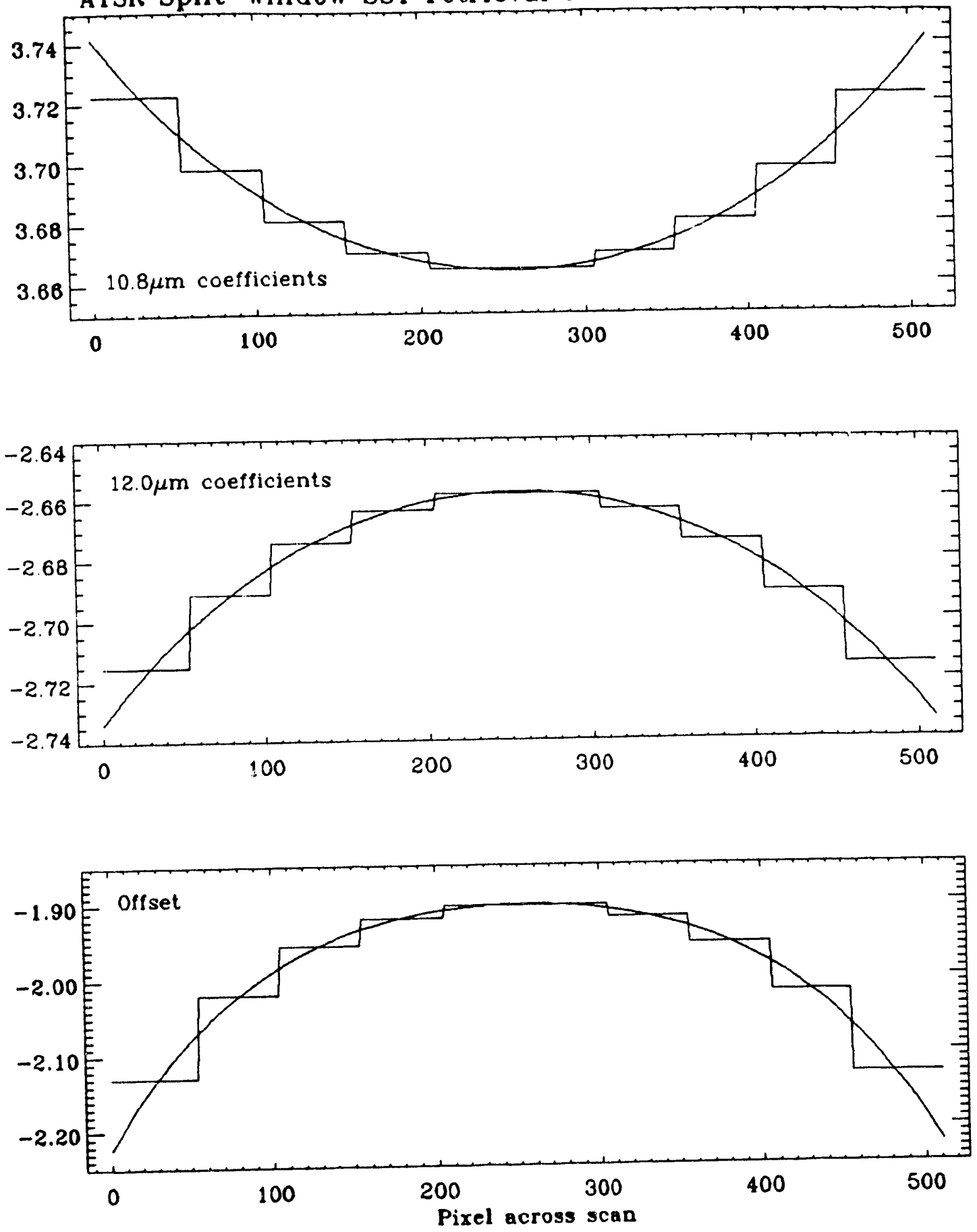

Figure 4. Coefficients for the sea-surface temperature retrieval from ATSR data, using a) the split-window atmospheric correction applied to measurements from the nadir swath data only, and b) the dual-angle split-window atmospheric correction. The coefficients are shown as functions of pixel number across the swath. The smooth curves are derived by fitting a fourthorcier polynomial to the stepped values, provided by Albin Zavody. 
ATSR dual-angle SST retrieval coefficients. Mid latitude.
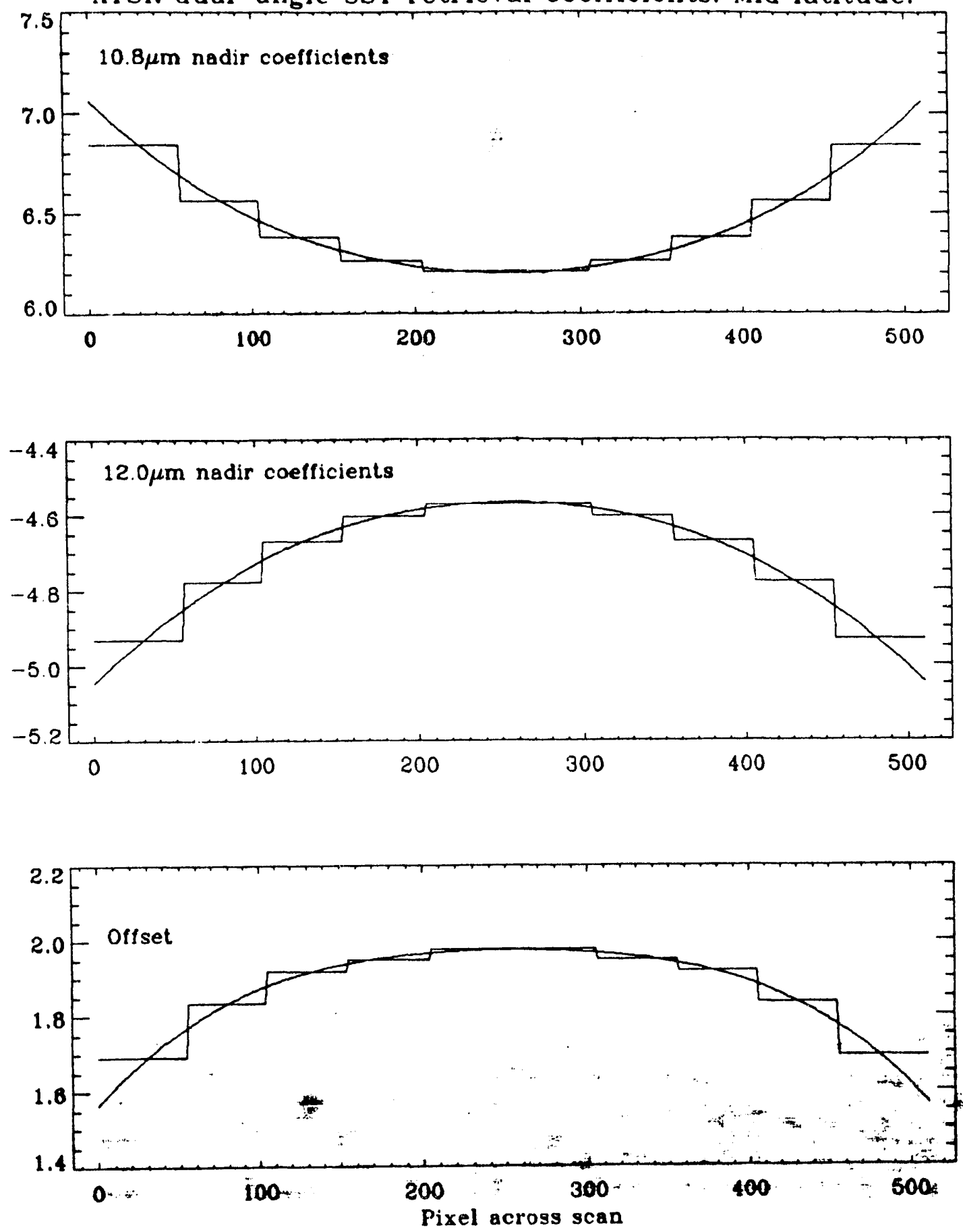

Figure 4 (continued). 

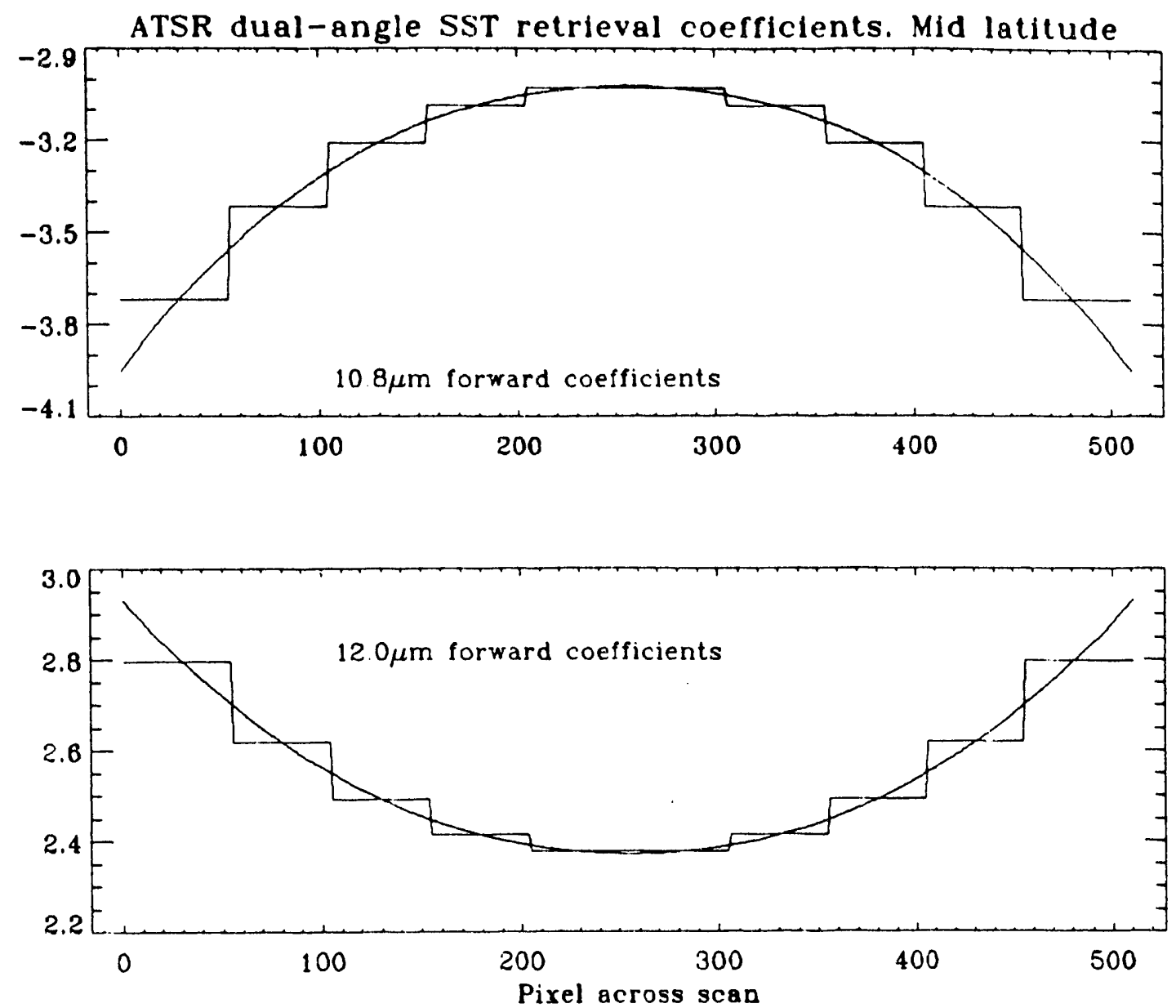

Figure 4 (continued). 


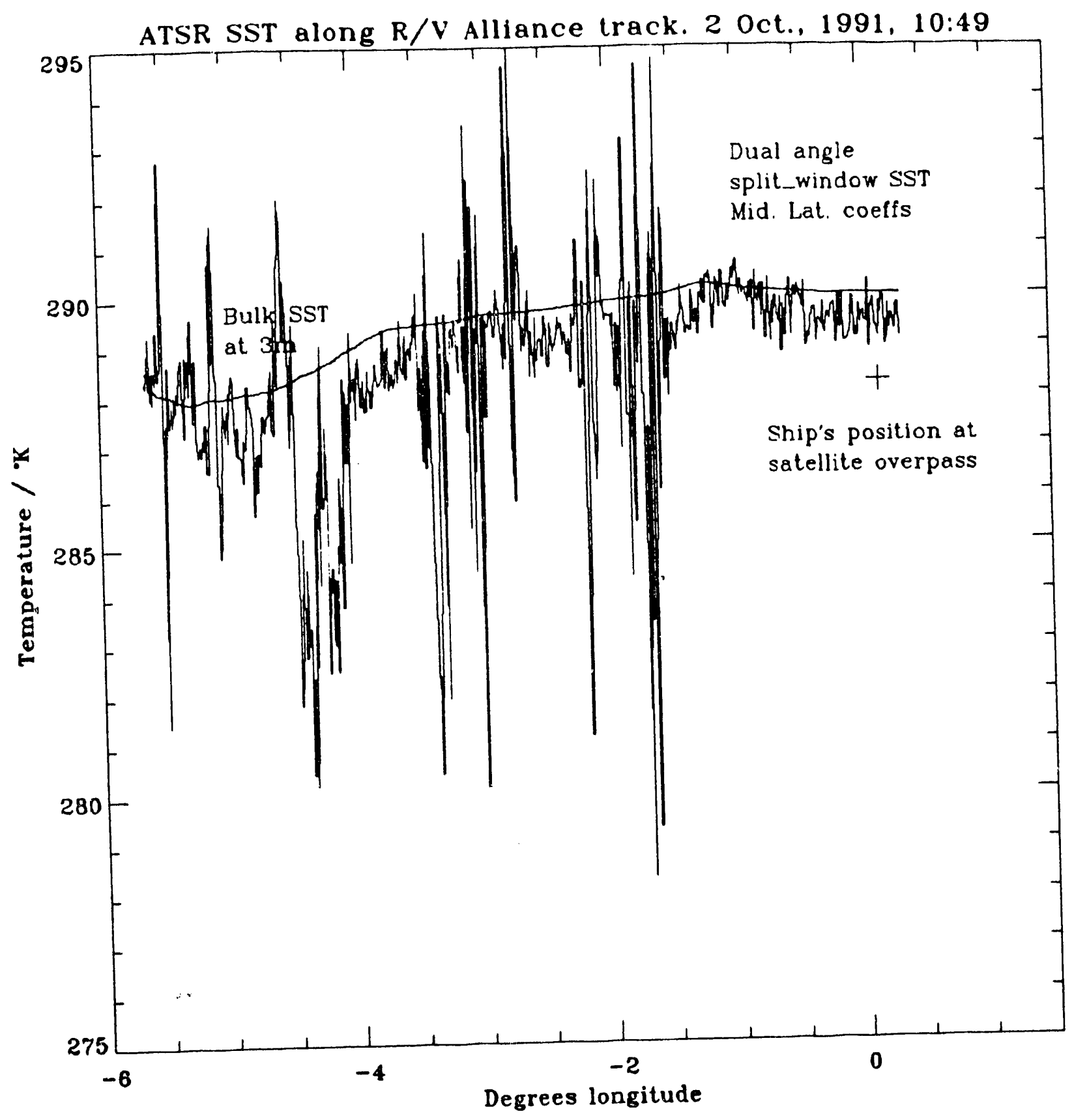

Figure 5. SST derived from the ATSR brightness temperature sections along the track of the ship for the image taken on October 2, 1991. The SSTs were calculated using mid-latitude coefficients for the nadir measurements at 10.8 and $12 \mu \mathrm{m}$. The $-3 \mathrm{~m}$ in situ SST trace is also shown. The position of the ship at the time of the satellite overpass is marked by a ' + '. 


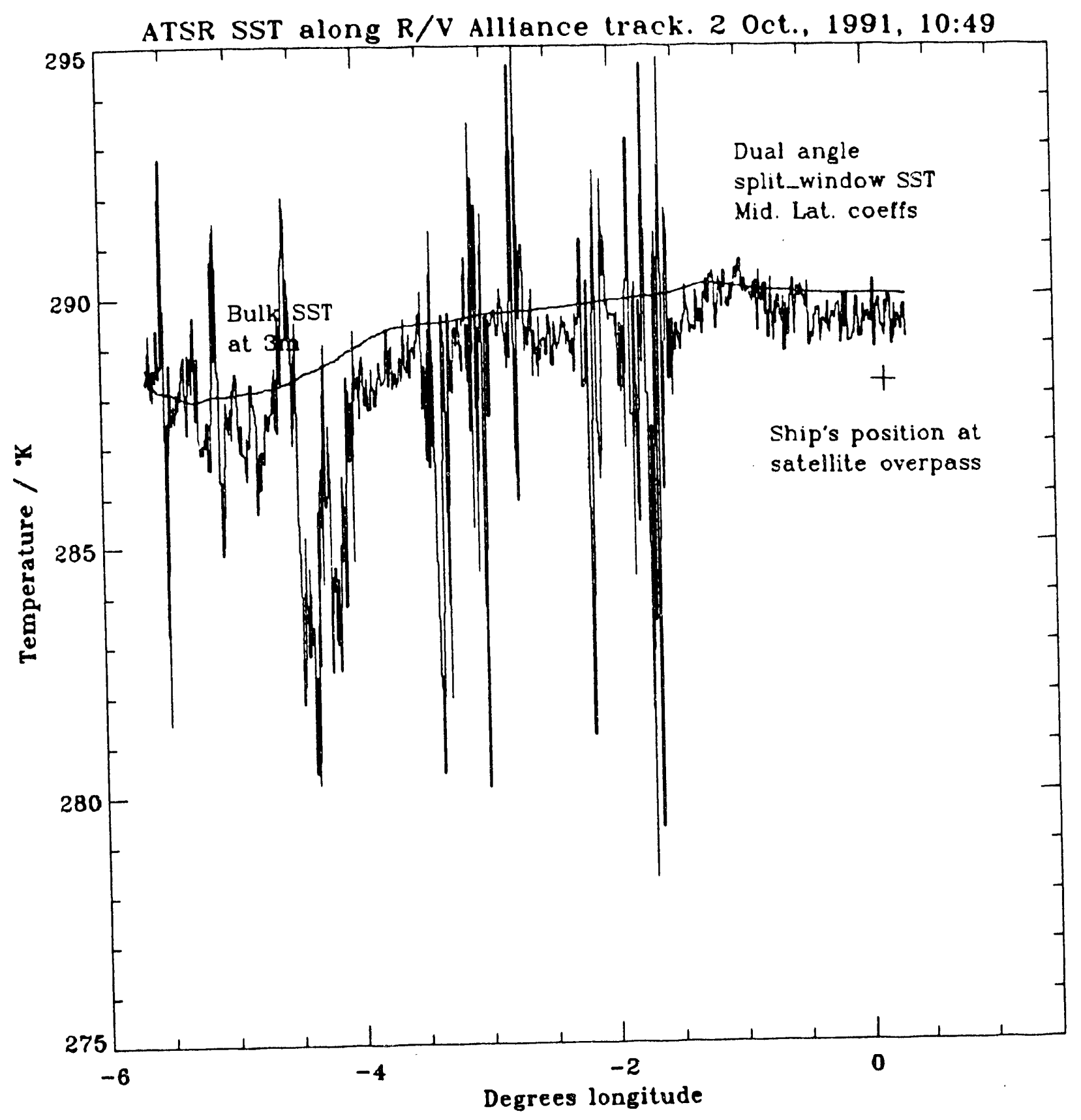

Figure 6. SST derived from the ATSR brightness temperature sections along the track of the ship for the image taken on October 2, 1991. The SSTs were calculated using mid-latitude coefficients for nadir and forward-view measurements at 10.8 and $12 \mu \mathrm{m}$. The $-3 \mathrm{~m}$ in situ SST trace is also shown. The position of the ship at the time of the satellite overpass is marked by a 't'. 


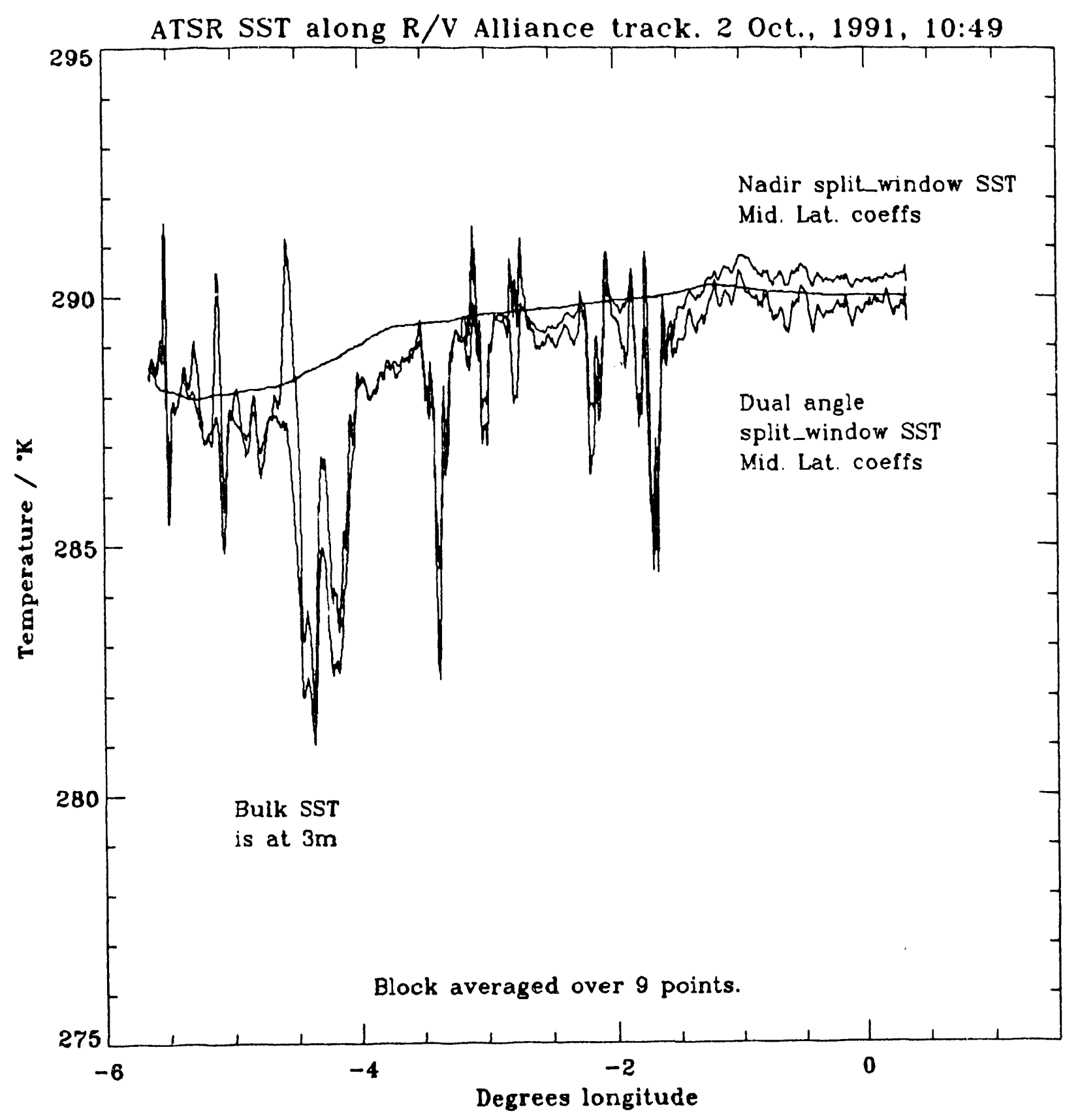

Figure 7. SSTs derived with the nadir split-window and dual-view split-window algorithms, smoothed by block averaging over 9 samples along the track. The $-3 \mathrm{~m}$ bulk temperature trace is also shown. The data are for the October 2 case. 


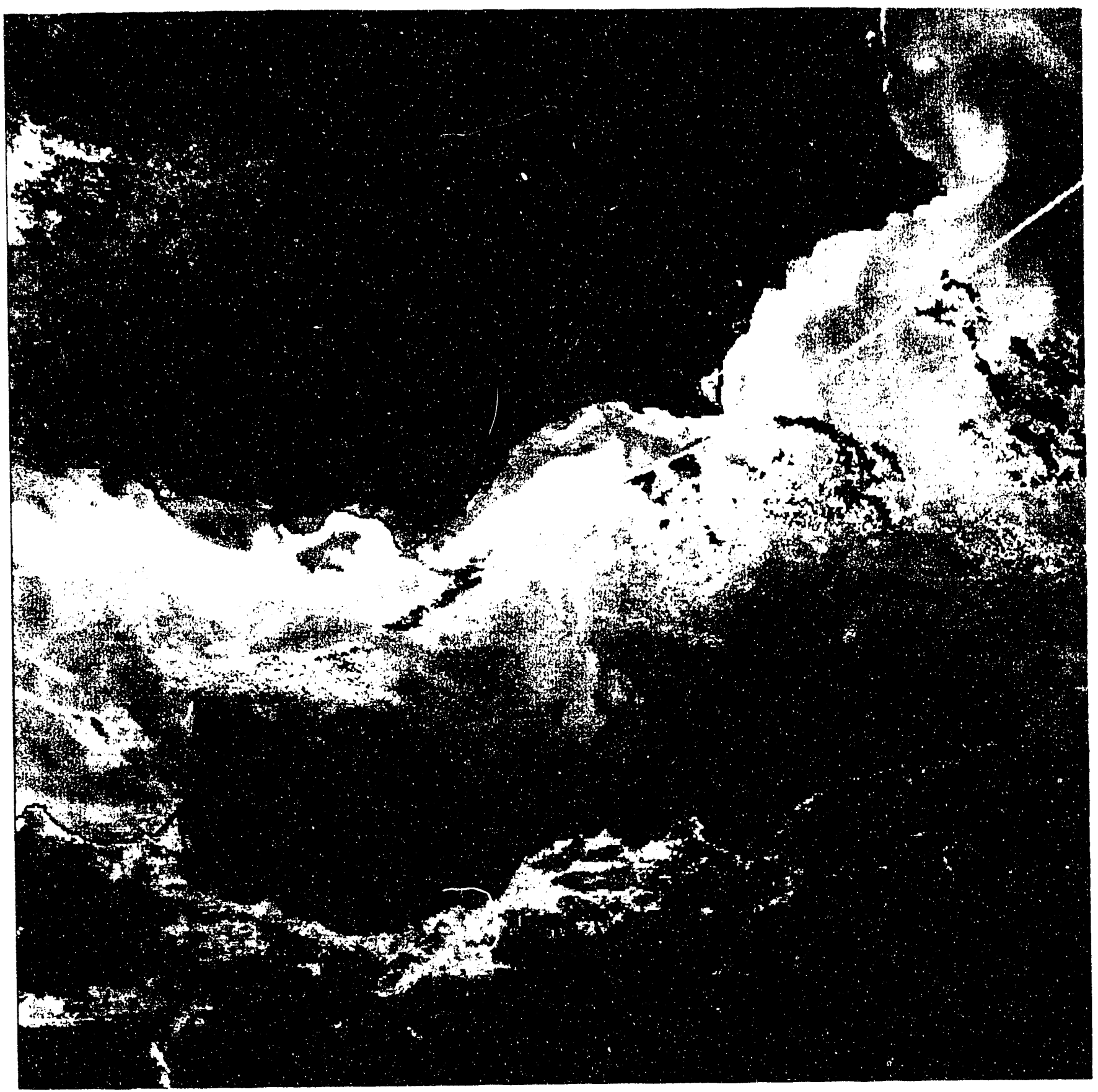

$\therefore \quad$ s.

$\therefore 3$.

ant? 5

$\therefore$

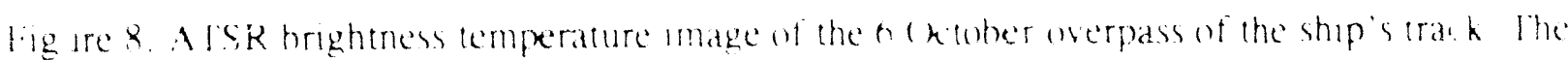

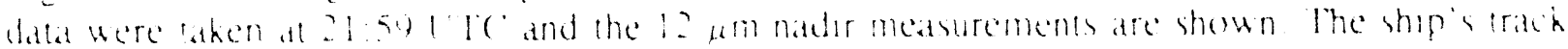

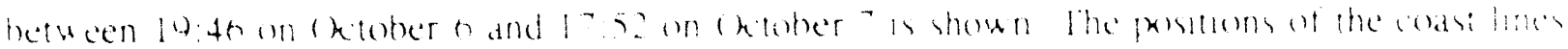

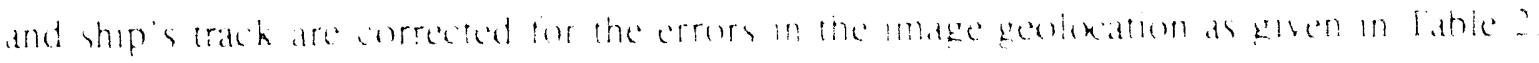




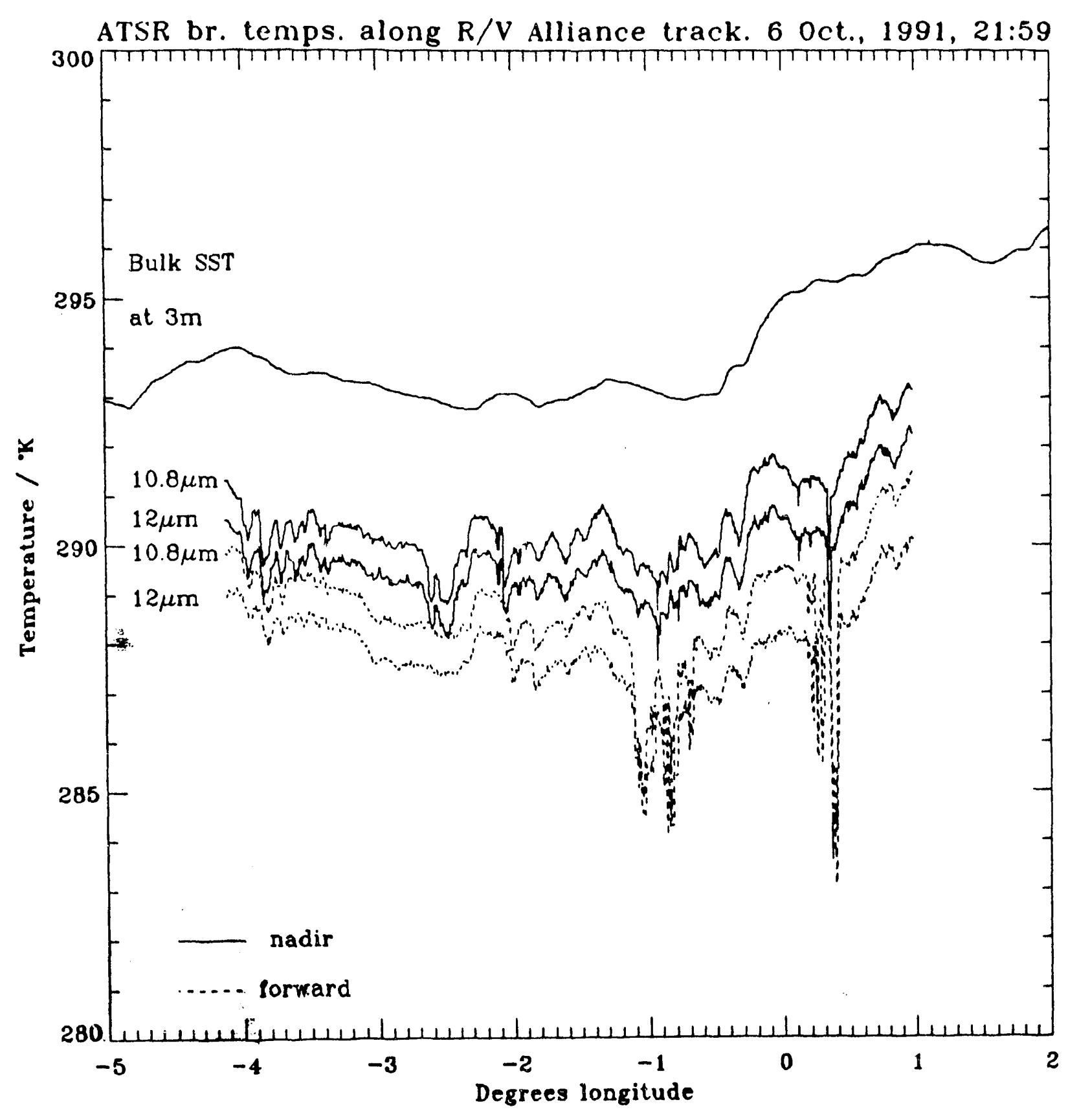

Figure 9. ATSR brightness temperature sections with the $-3 \mathrm{~m}$ in situ SST along the track of the ship for the image taken on October 6, 1991. 


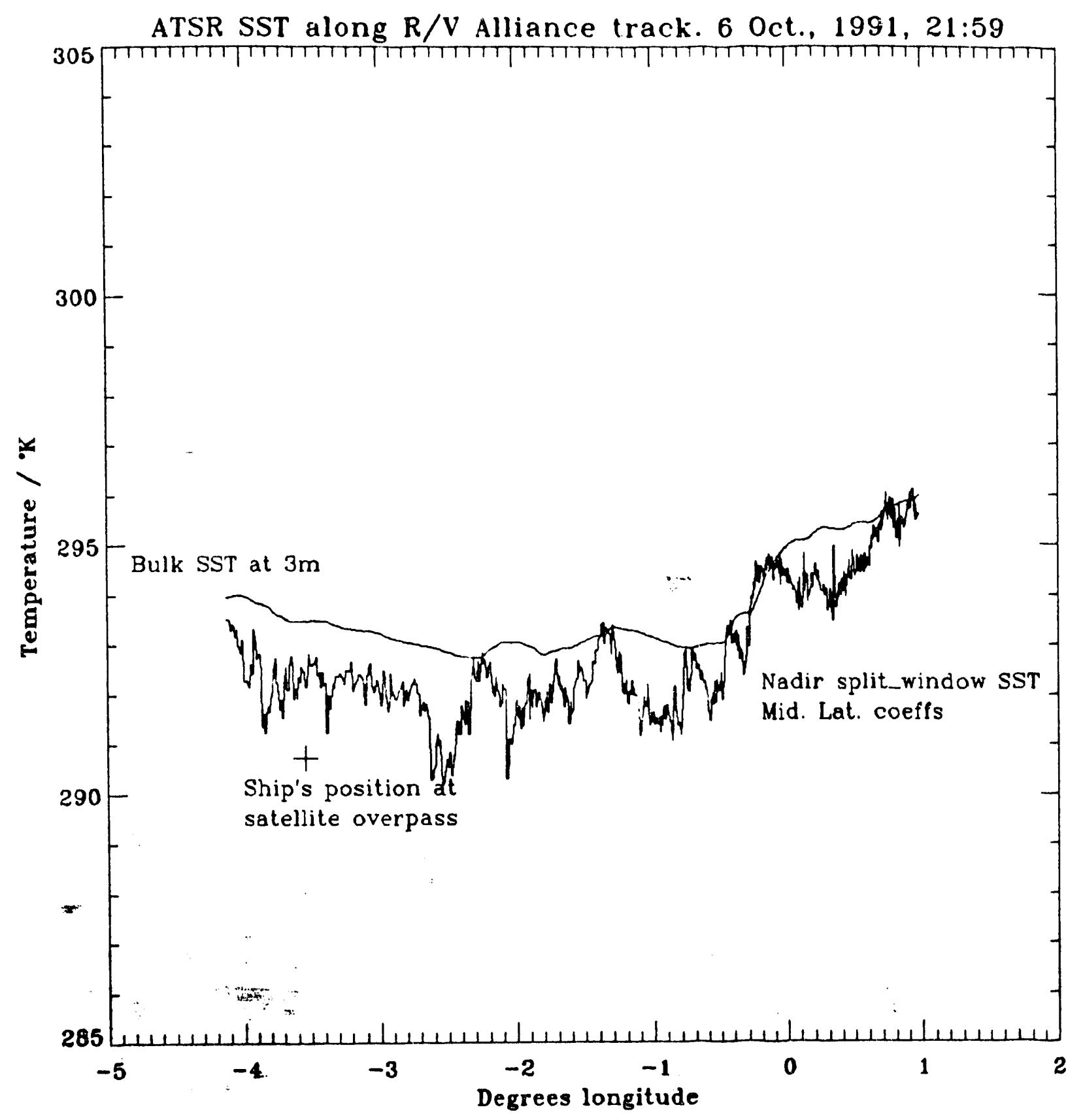

Figure 10. SST derived from the ATSR brightness temperature sections along the track of the ship for the image taken on October 6, 1991. The SSTs were calculated using mid-latitude coefficients for the nadir measurements at 10.8 and $12 \mu \mathrm{m}$. The $-3 \mathrm{~m}$ in situ SST trace is also shown. The position of the ship at the time of the satellite overpass is rnarked by a ' + '. 


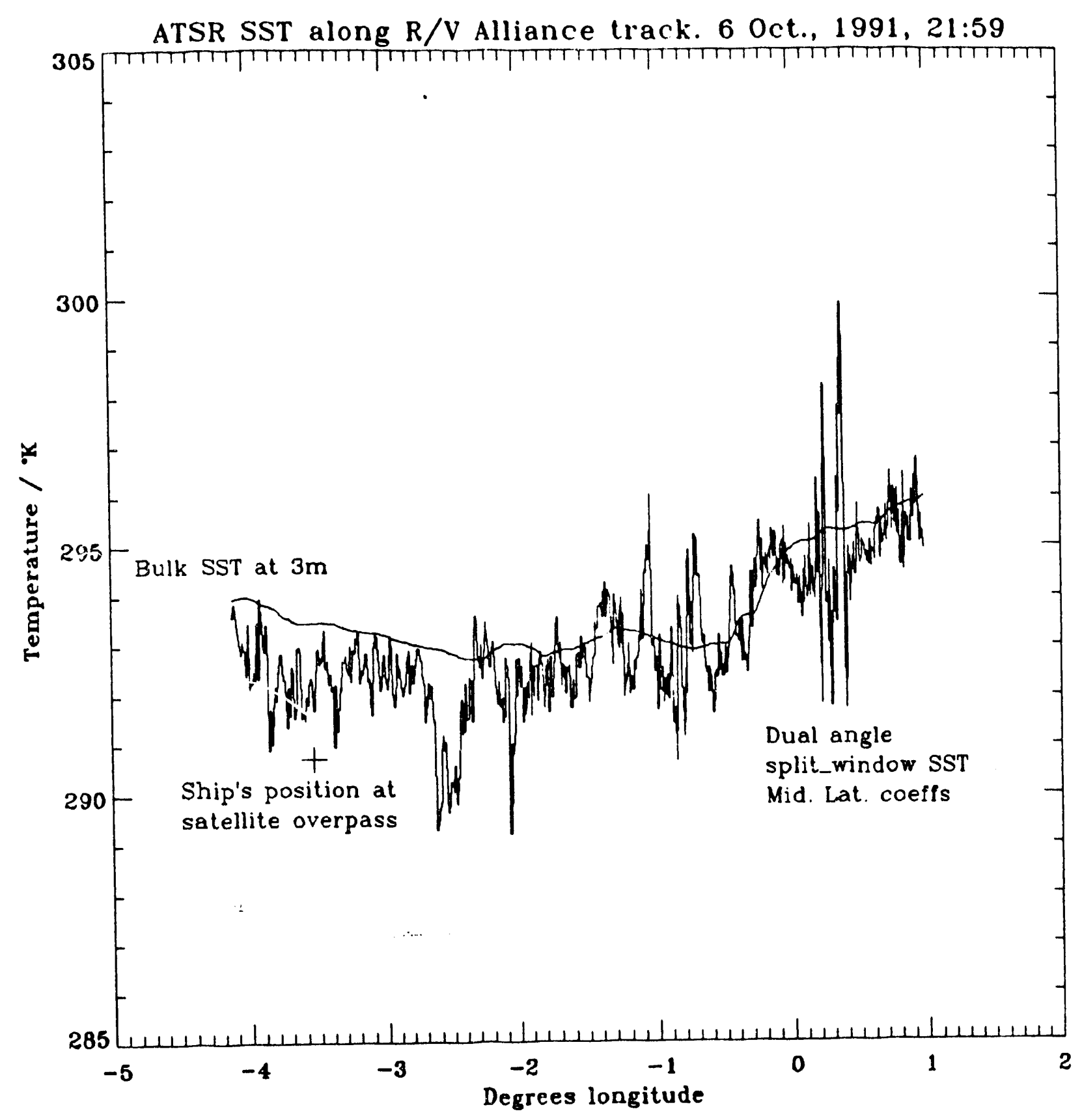

Figure 11. SST derived from the ATSR brightness temperature sections along the track of the ship for the image taken on October 6, 1991. The SSTs were calculated using mid-latitude coefficients for nadir and forward-view measurements at 10.8 and $12 \mu \mathrm{m}$. The $-3 \mathrm{~m}$ in situ SST trace is also shown. The position of the ship at the time of the satellite overpass is marked by a ' + '. 


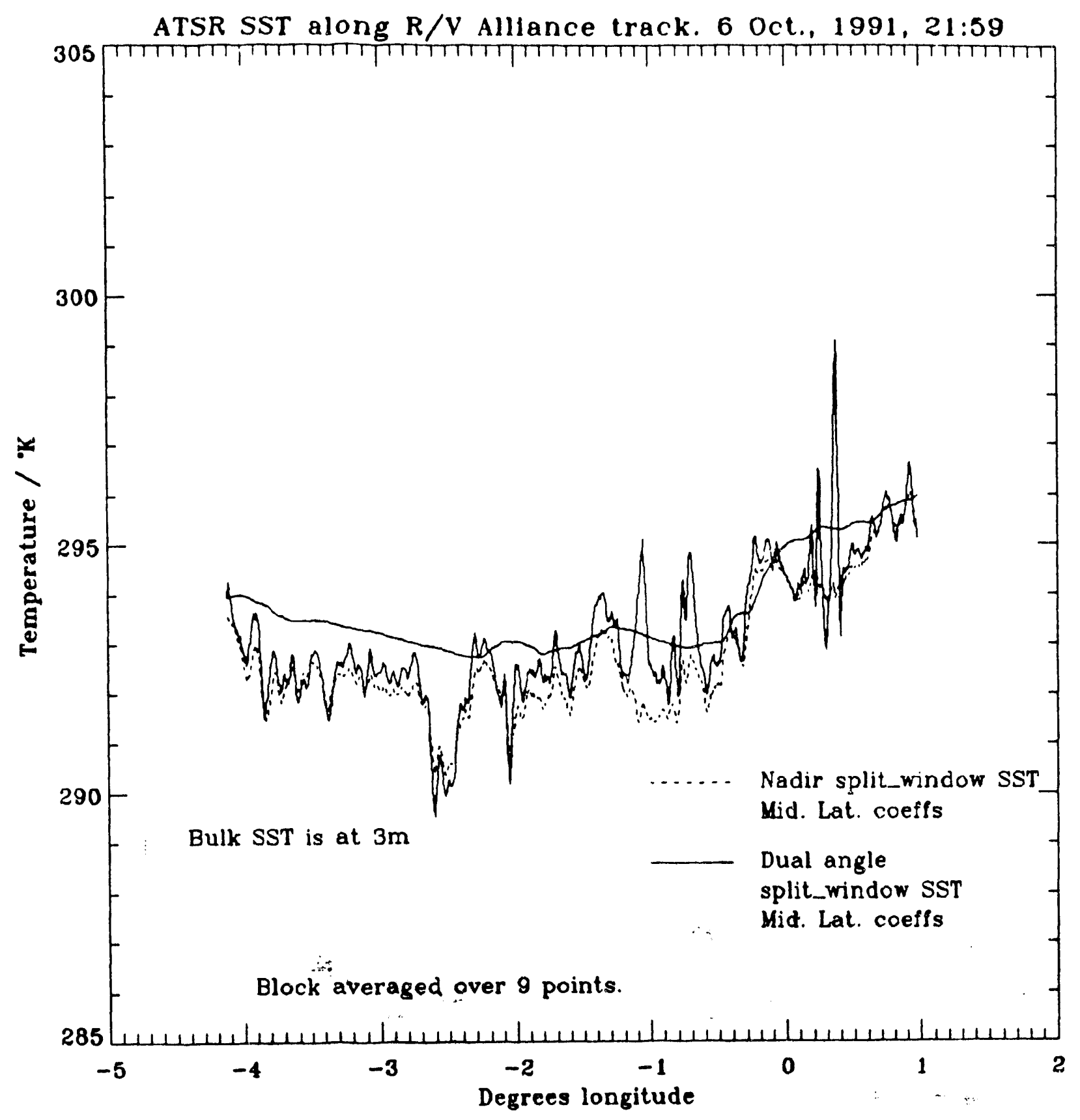

Figure 12. SSTs derived wiin the nadir split-window and dual-view split-window algorithms, smoothed by block averaging over 9 samples along the track. The $-3 \mathrm{~m}$ bulk temperature trace is also shown. The data are for the October 6 case. 
ATSR 2 October. Nadir split window SST.

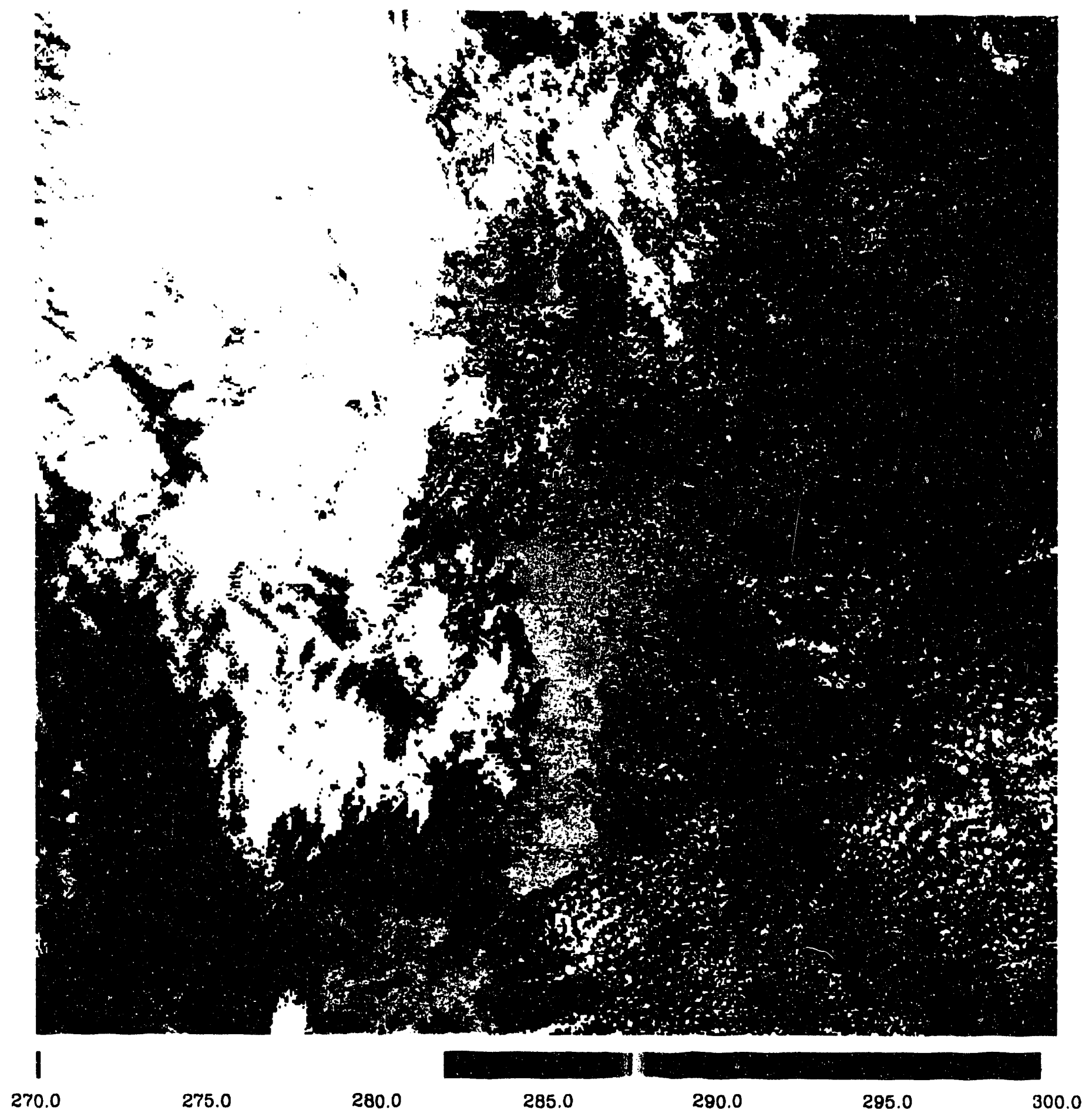

Figure 13. SST image for October 2 derived using the nadir swath split-window atmospheric correction. 
ATSR 2 October. Dual angle split window SST.

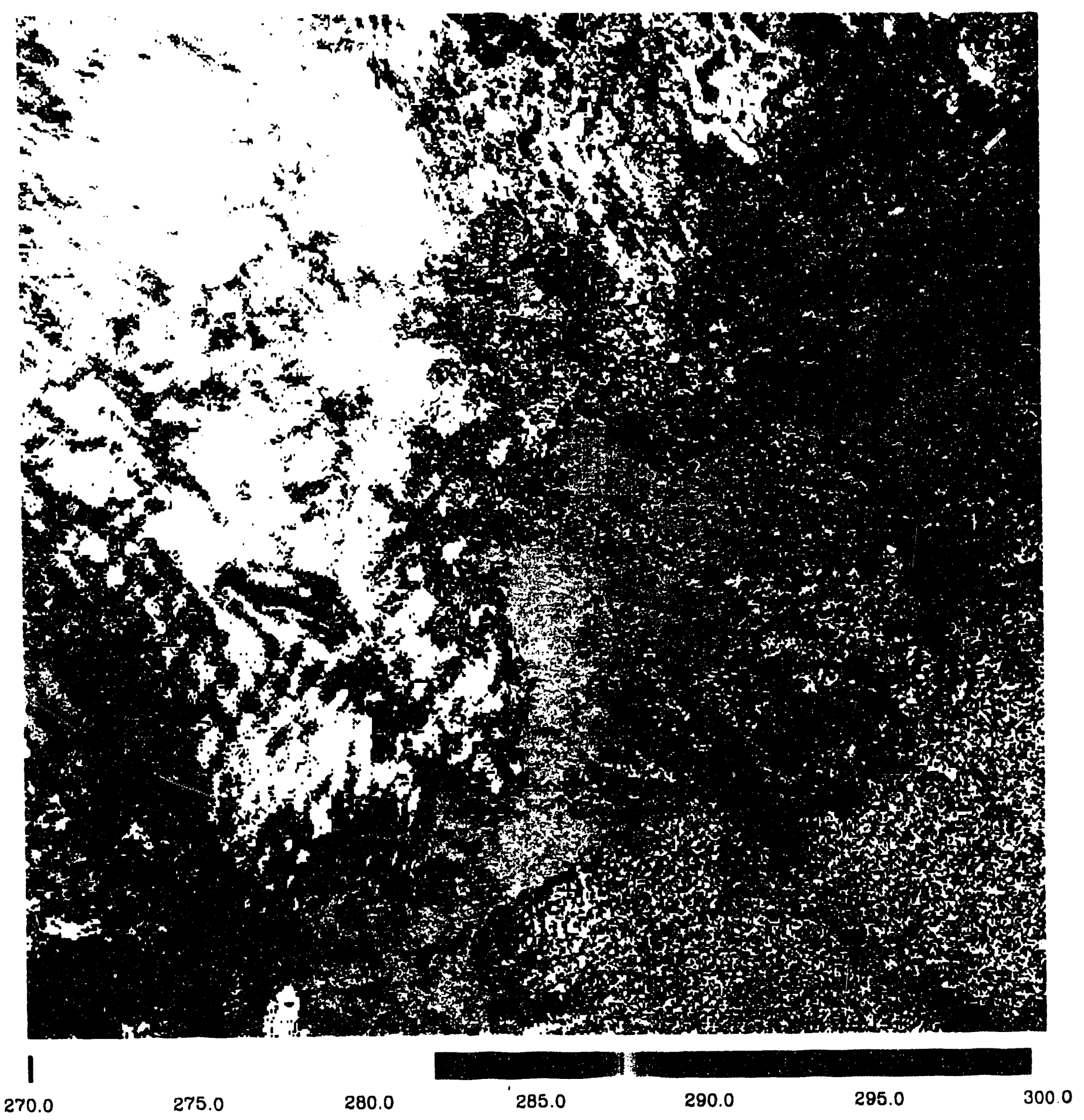

Figure 14. SST image for October 2 derived using the dual-angle split-window atmospheric correction, without correction of the position of the forward swath data. 
ATSR 2 October. Dual angle split window SST.

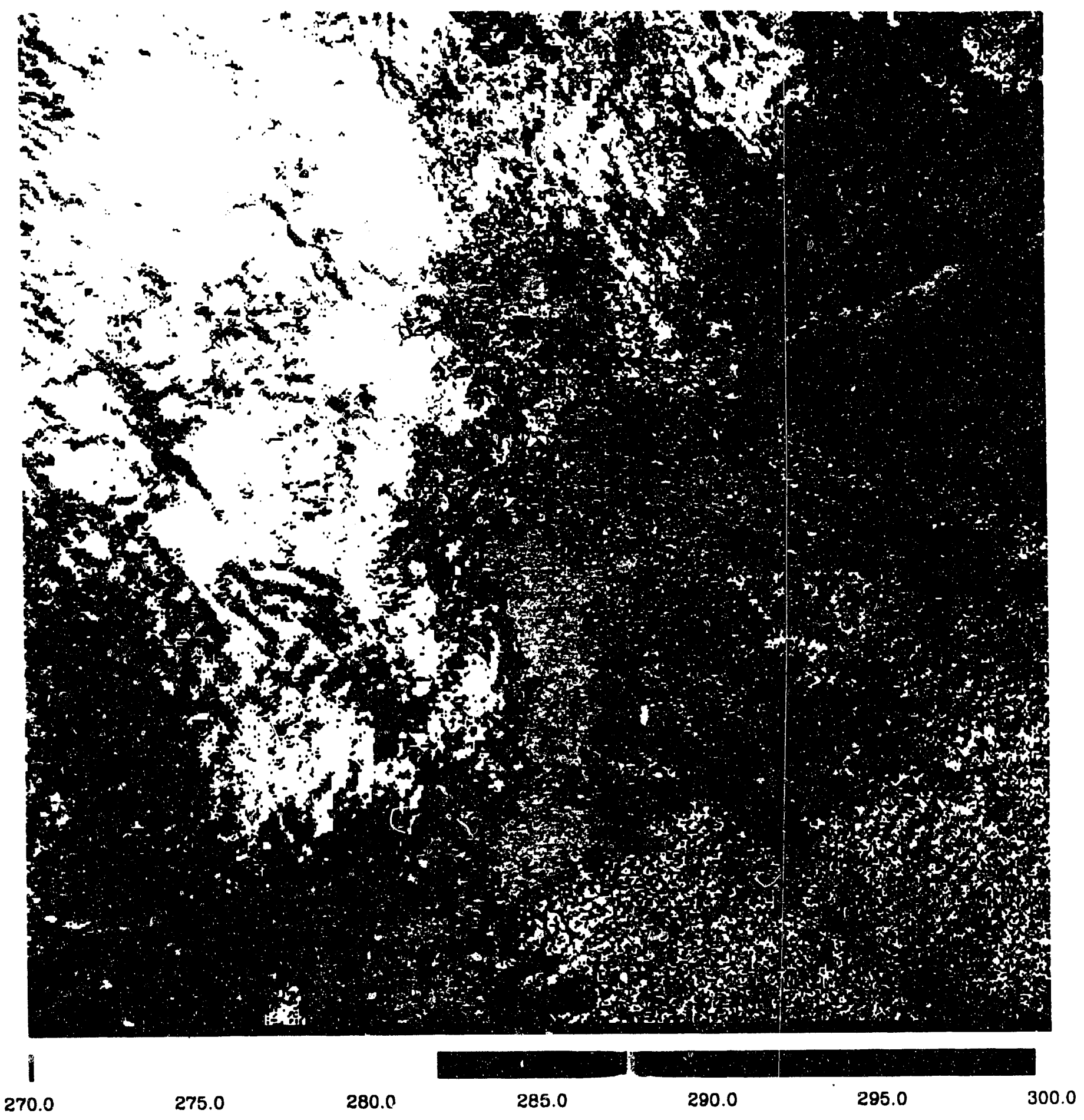

Figure 15. SST image for October 2 derived using the dual-angle split-window atmospheric correction, with correction of the position of the forward swath data. 


\section{ATSR 6 October 1991. Split window SST}

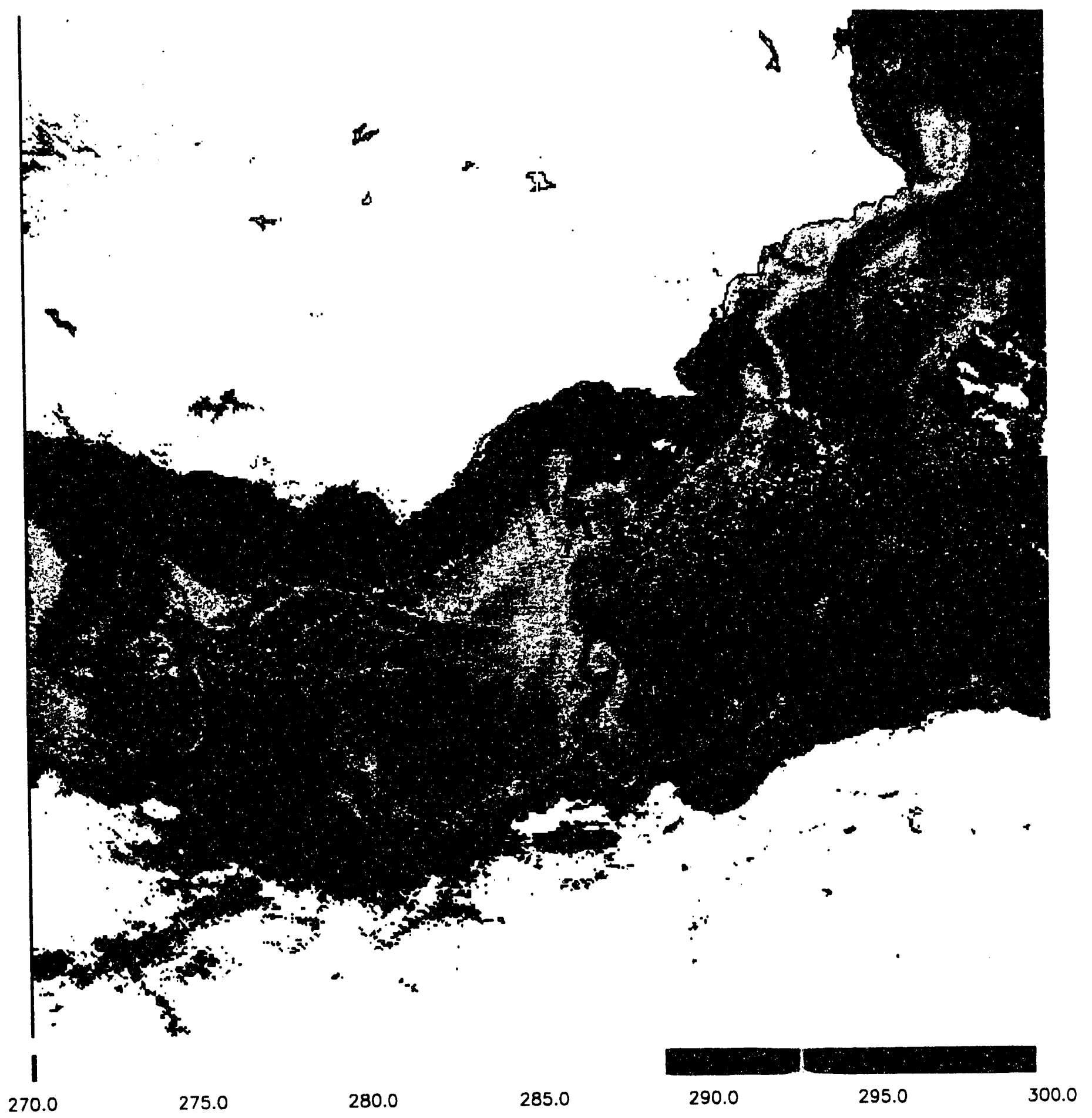

Figure 16. SST image for October 6 derived using the nadir swath split-window atmospheric correction. 


\section{Al'SR 6 October. 1991. Dual angle s.te diffs}

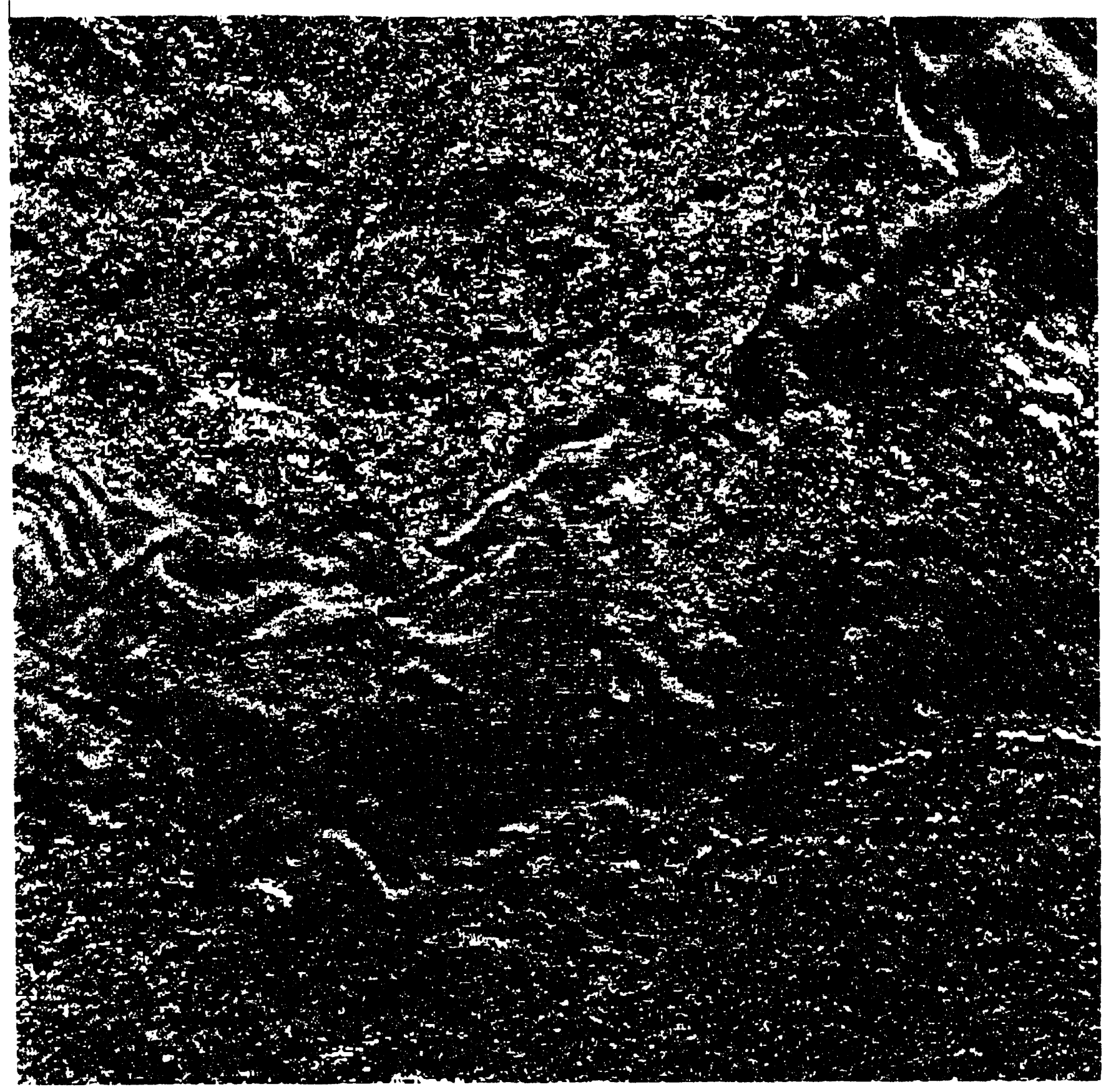

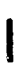

$-50$
$-33$

$-1.7$
铁期

00

Figure 17. SST image for October 6 derived using the dual-angle split-window atmospheric correction, without correction of the position of the forward swath data 


\section{ATSR 6 October 1991. Dual angle split window SST}

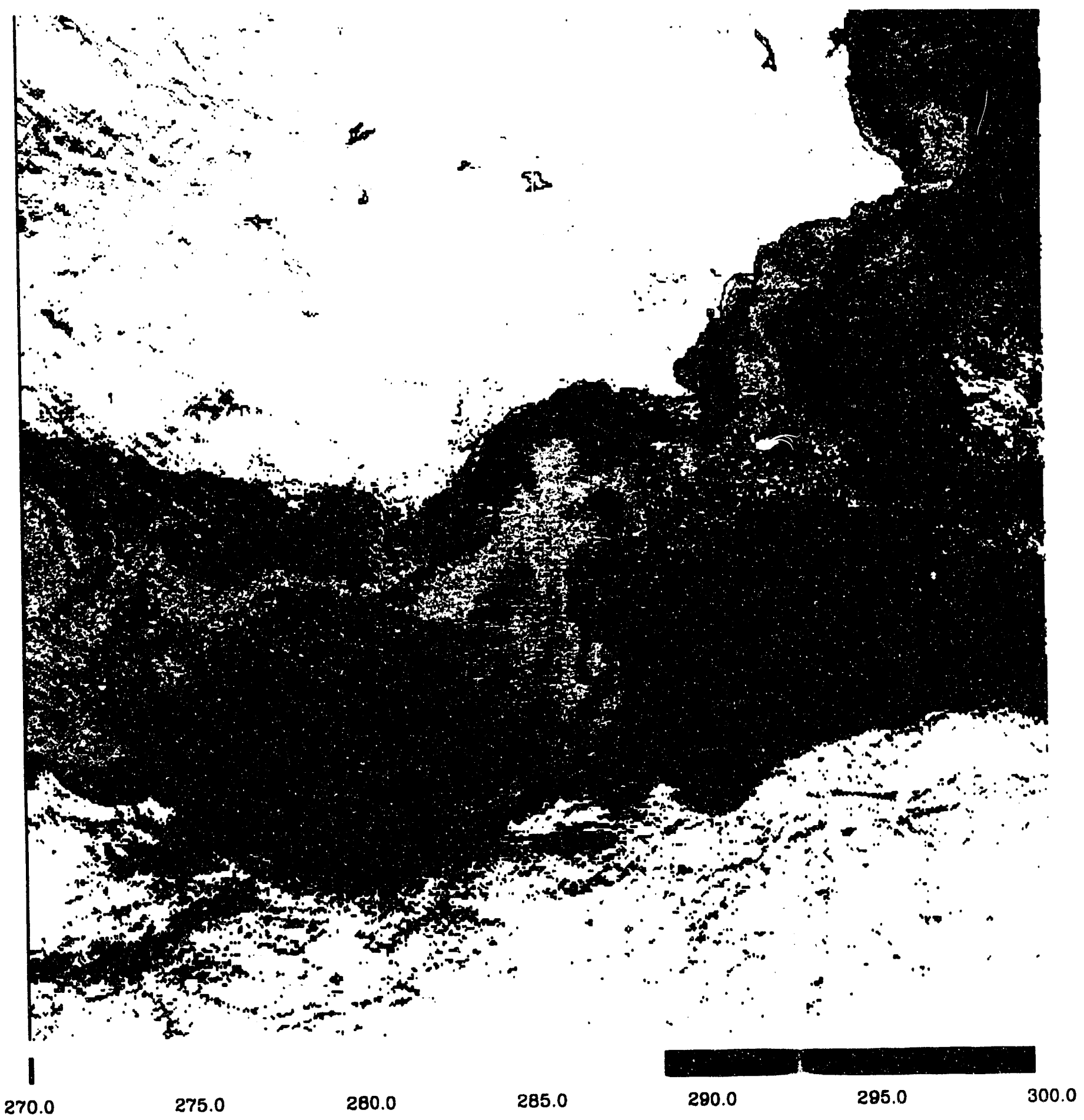

Figure 18. SST image for October 6 derived using the dual-angle split-window atmospheric correction, with correction of the position of the forward swath data. 


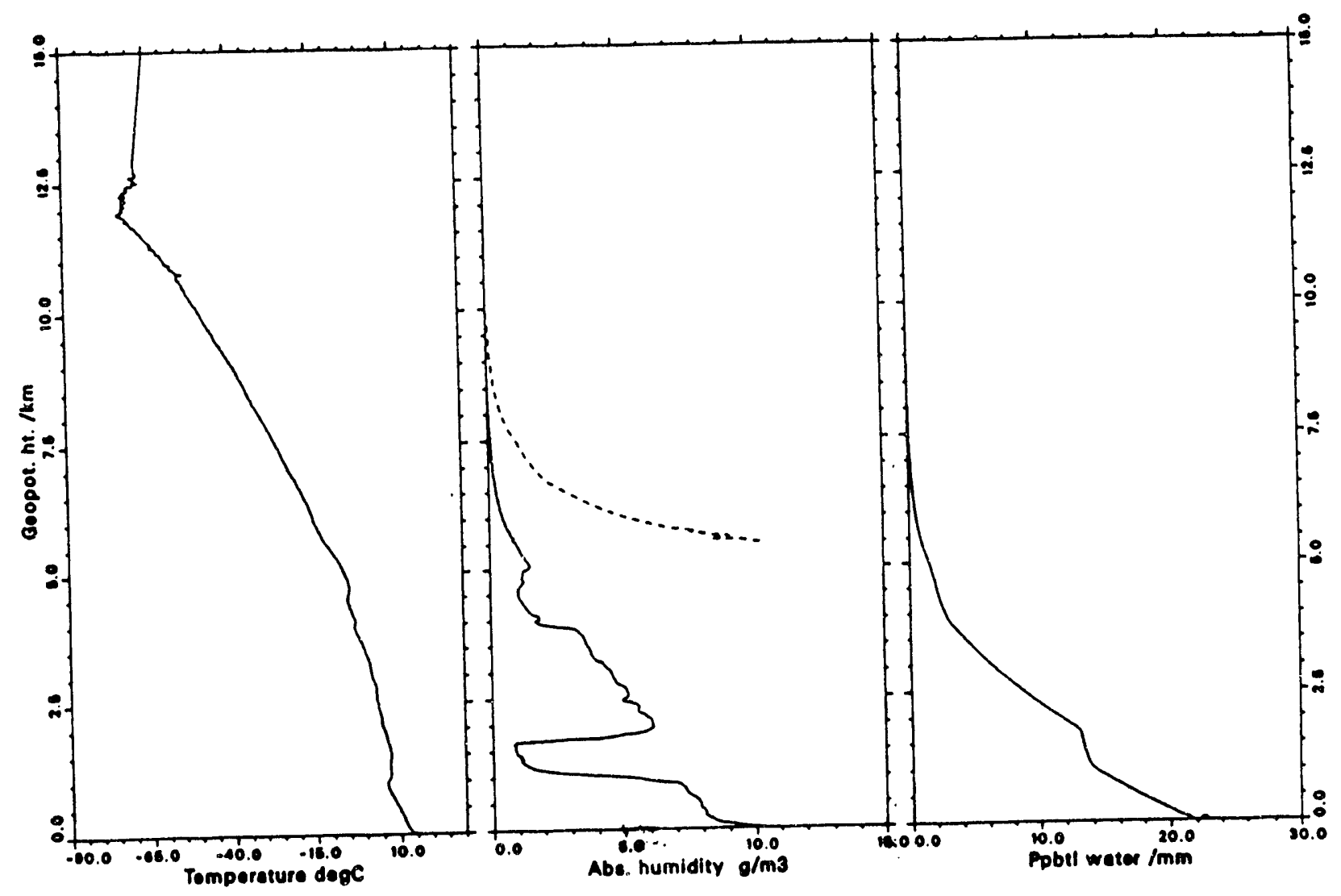

Figure 19. Atmospheric profiles of temperature, absolute humidity and precipitable water derived from a radiosonde launched from the R/V Alliance at 14:46 on October 2. The dashed line in the absolute humidity panel is the profile, magnified by a factor of 10 , for the upper region where the values are less than $1 \mathrm{~g} \mathrm{~m}^{-3}$. The precipitable water is $21.83 \mathrm{~mm}$. 

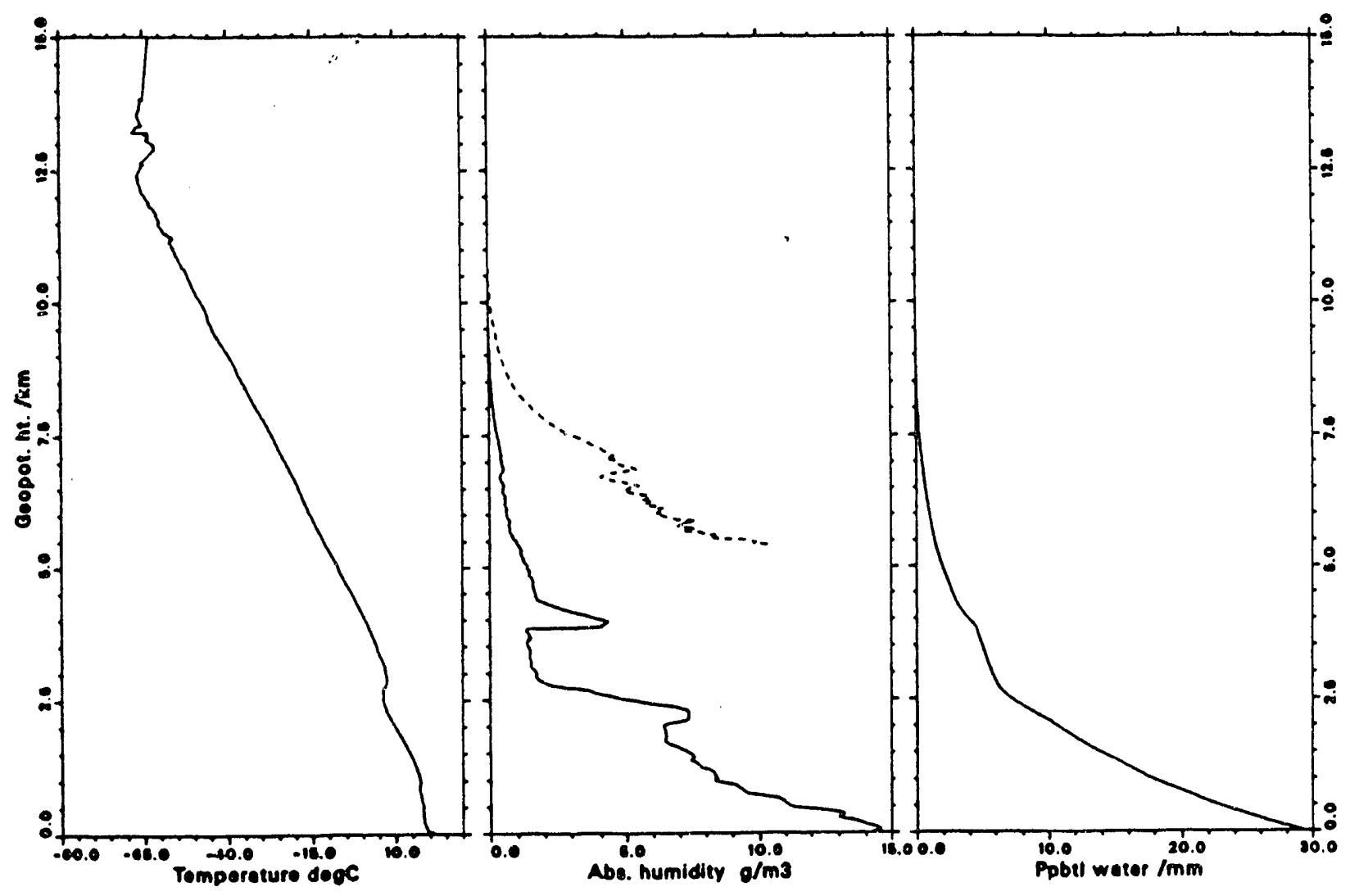

Figure 20. Atmospheric profiles of temperature, absolute humidity and precipitable water derived from a radiosonde launched from the R/V Alliance at 22:04 on October 6. The dashed line in the absolute humidity panel is the profile, magnified by a factor of 10 , for the upper region where the values are less than $1 \mathrm{~g} \mathrm{~m}^{-3}$. The precipitable water is $29.31 \mathrm{~mm}$. 


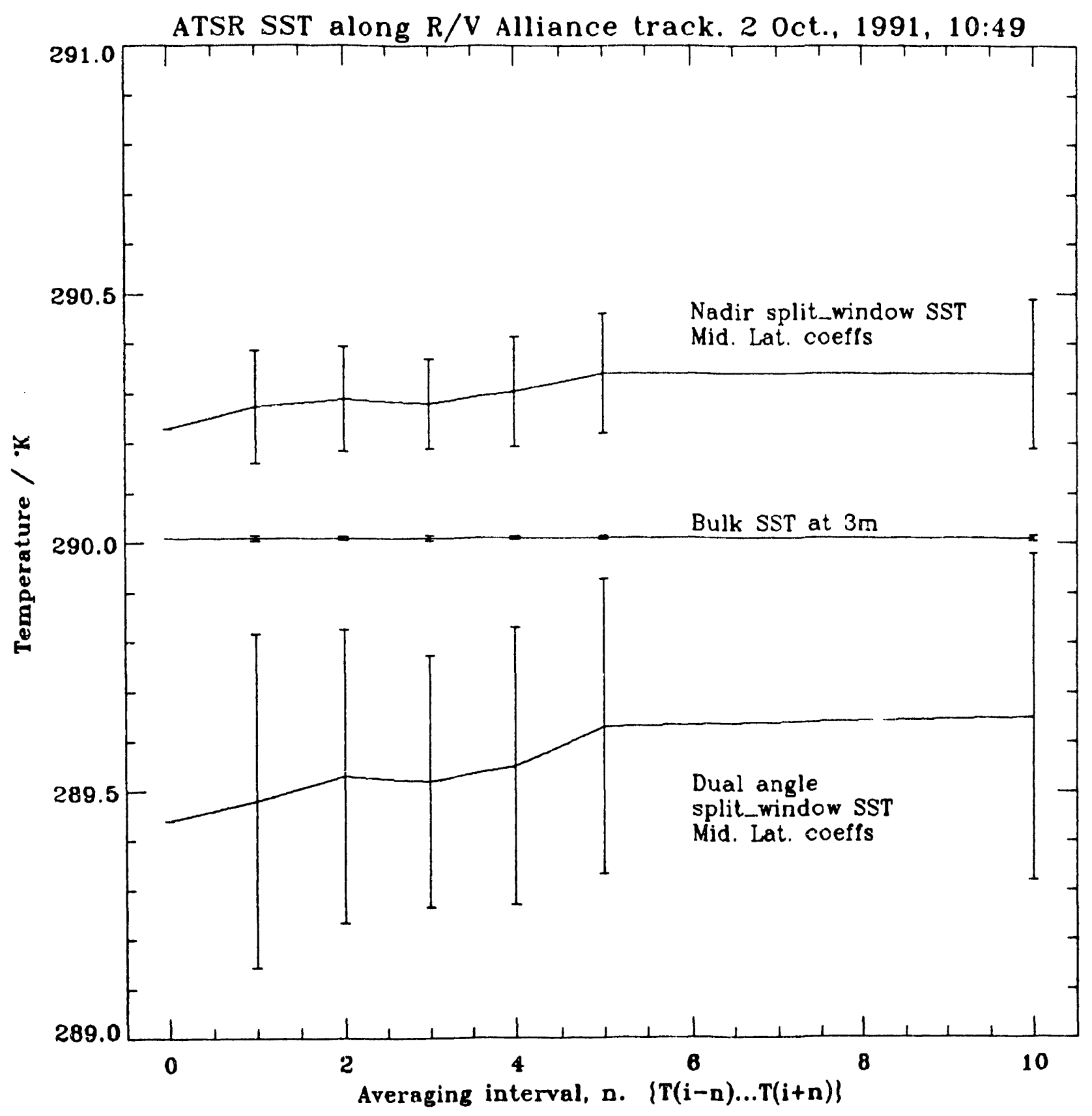

Figure 21. Effect on SST estimates of averaging along the track of the ship for the October 2 case. The error bars are the \pm one standard deviation in the averaging interval. 


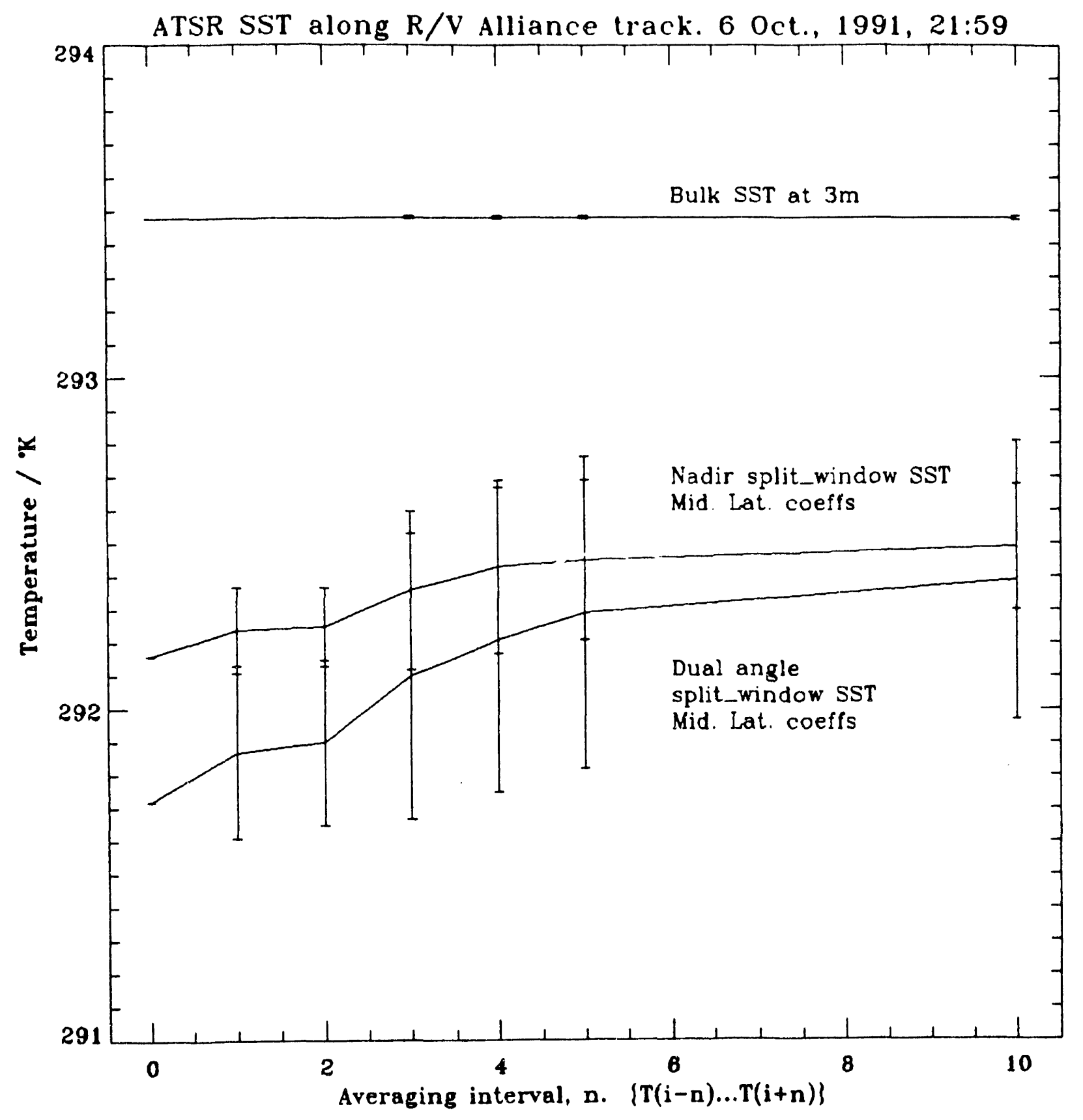

Figure 22. Effect on SST estimates of averaging along the track of the ship for the October 6 case. The error bars are the \pm one standard deviation in the averaging interval. 
ATSR 2 October 1991. Split window SST.

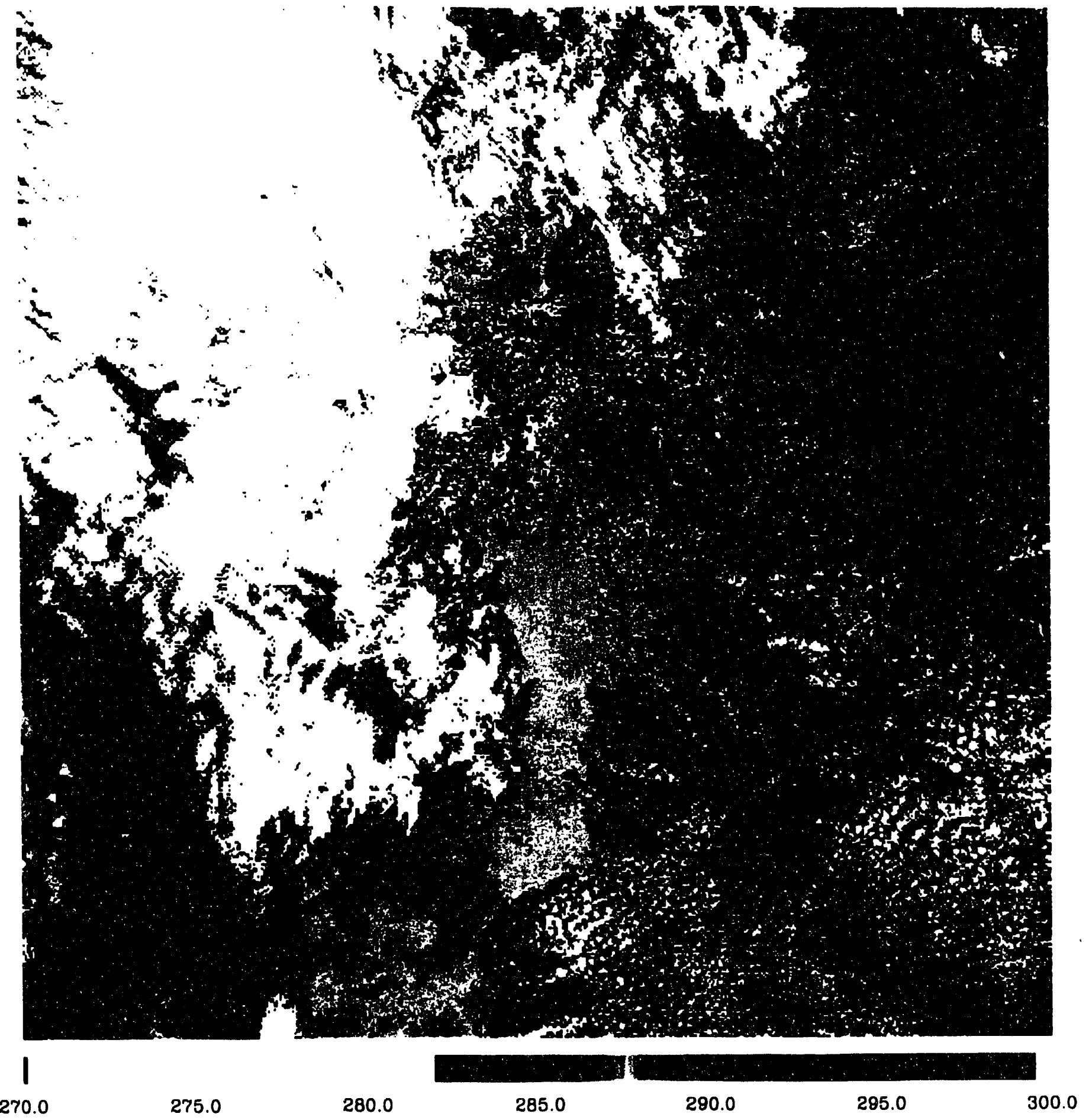

Figure 23. Position of the area used in the cloud-free SST comparisons, October 2. 
ATSR 6 October 1991. Split window SST.

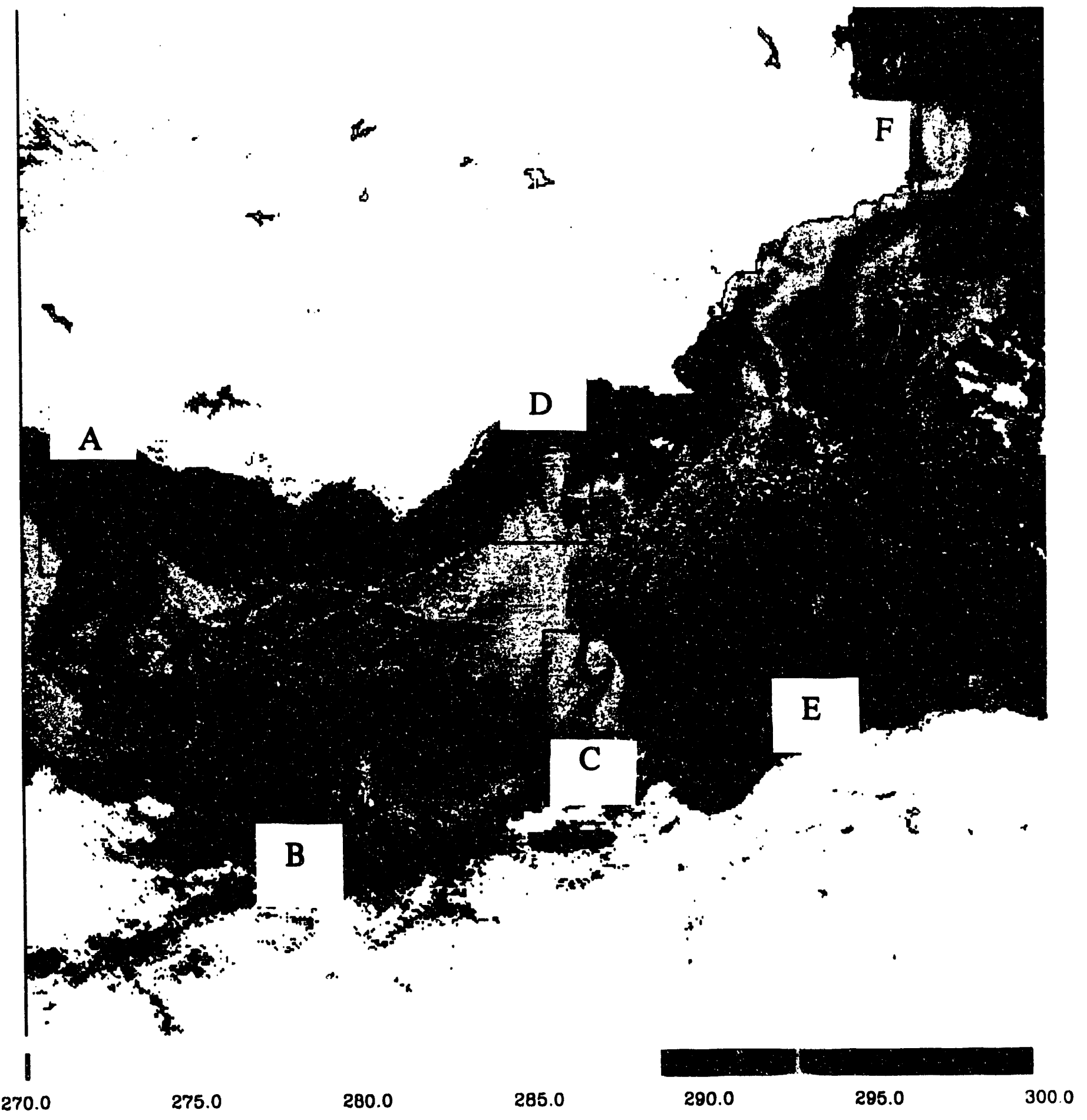

Figure 24. Positions of the areas used in the cloud-free SST comparisons, October 6. The areas were selected to span the width of the swath and to include areas with and without significant horizontal SST gradients. 
ATSR SST hIstograme 2 Ortober 1991.
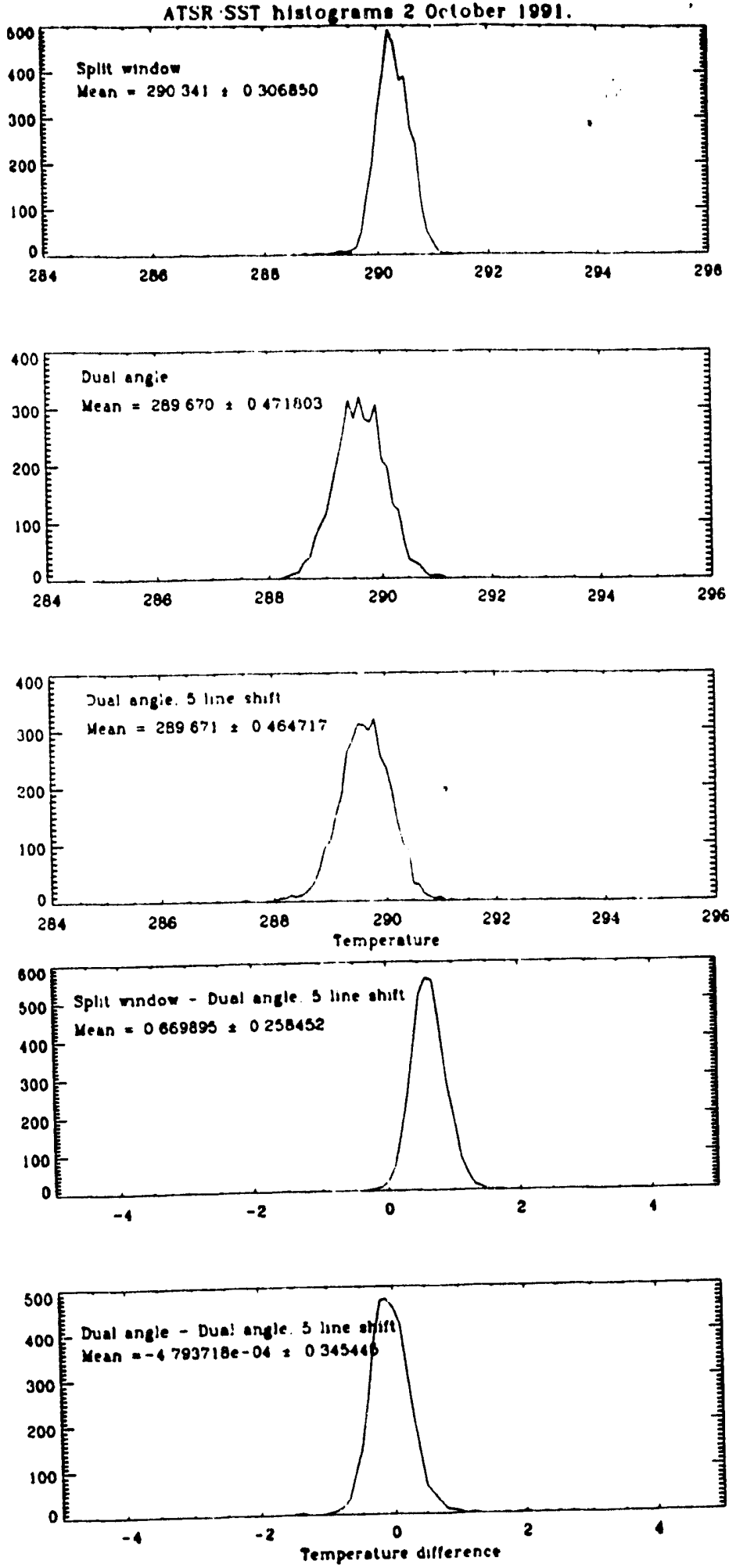

Figure 25. Histograms of the SST pixel values retrieved in the boxed area in Figure 23. Differences are shown referred to the dual-angle SST retrieval calculated using the corrected positions of the forward view measurements. 
ATSR SST histograms 6 October 1991. Area A
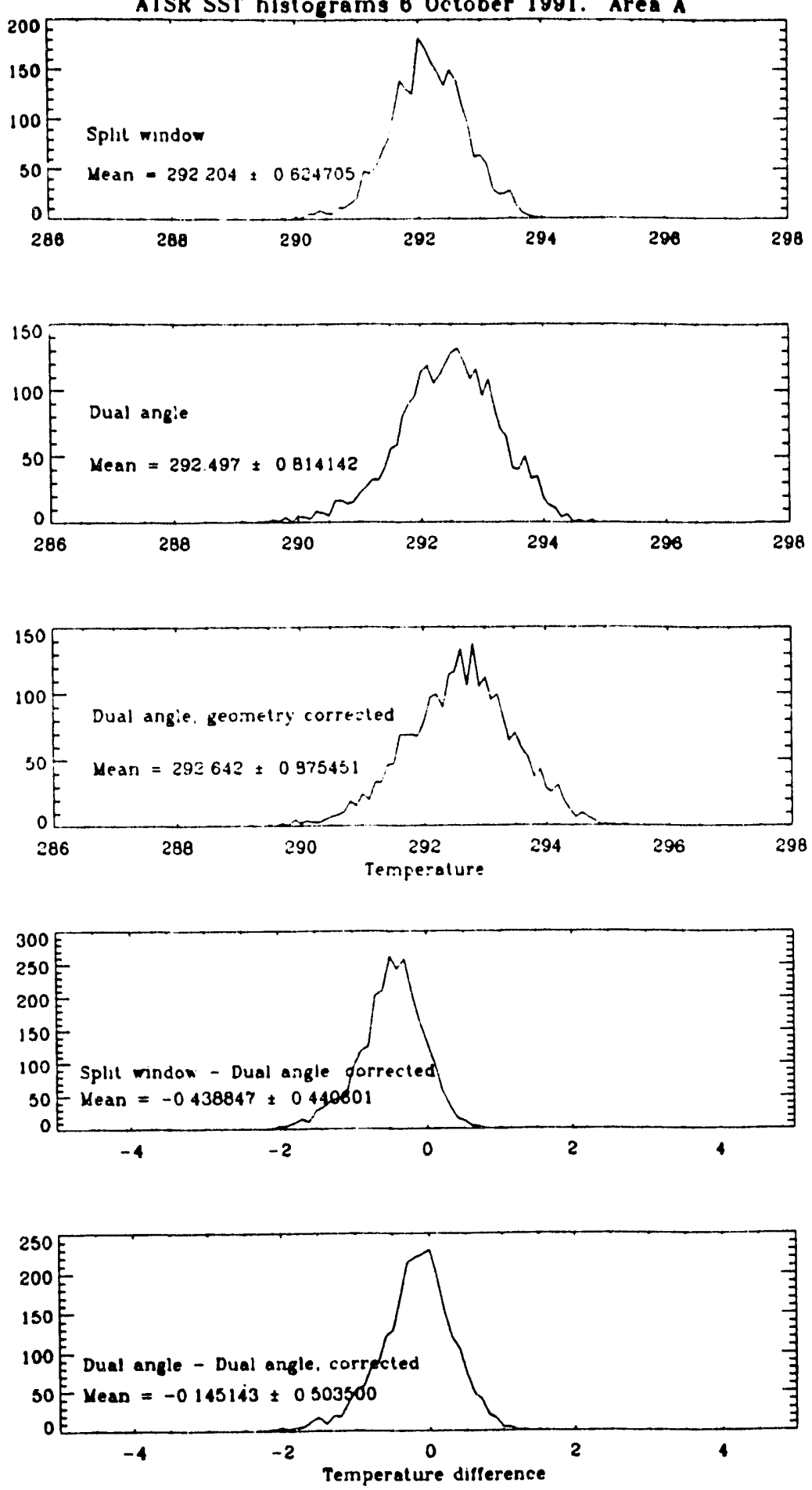

Figure 26. Histograms of the SST pixel values retrieved in the boxed area A in Figure 24. Differences are shown referred to the dual-angle SST retrieval calculated using the corrected positions of the forward view measurements. 
ATSR SST histograms 6 Ortober 1891. Area B
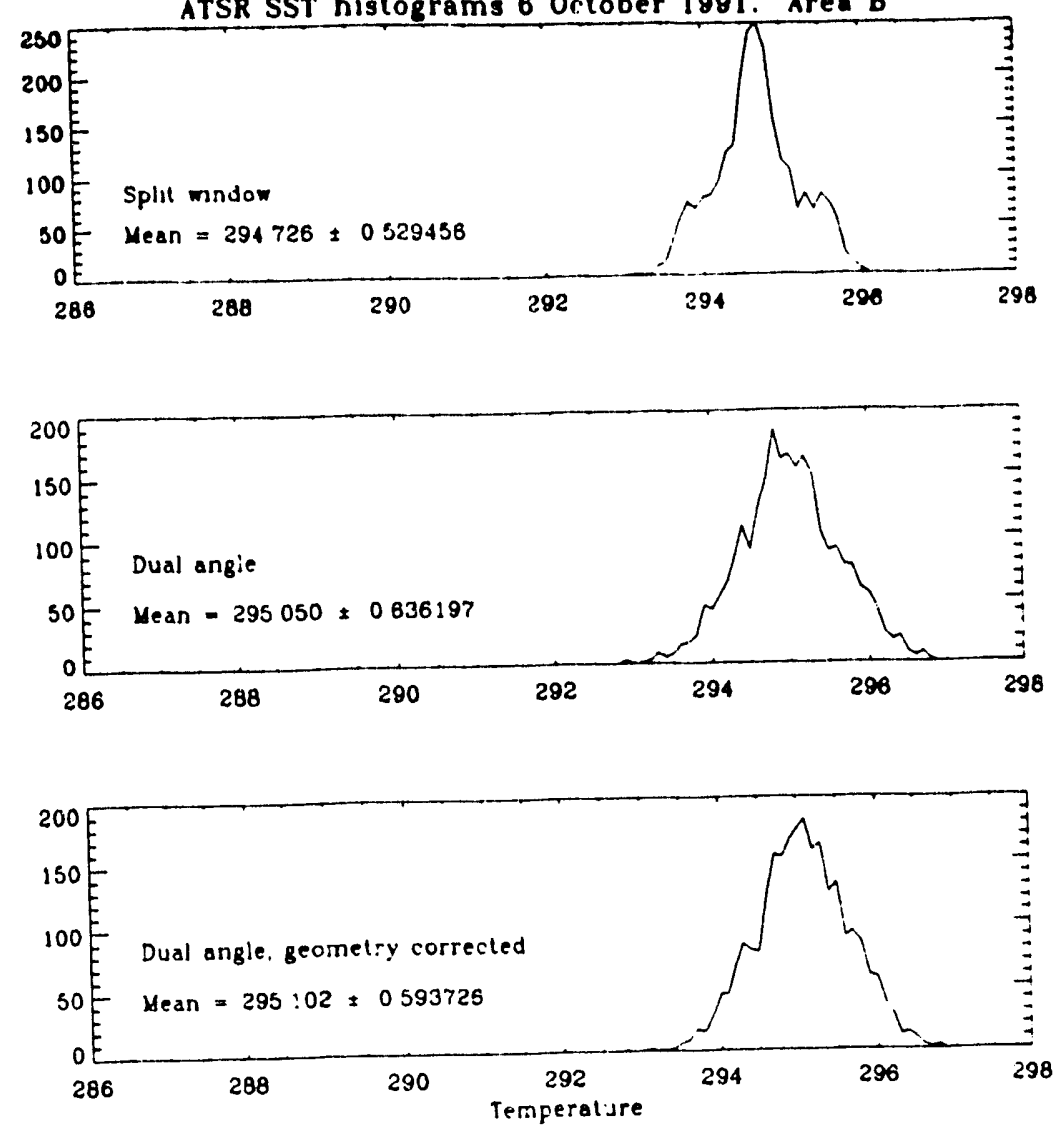

ATSR SST histograms 6 October 1991. Area B
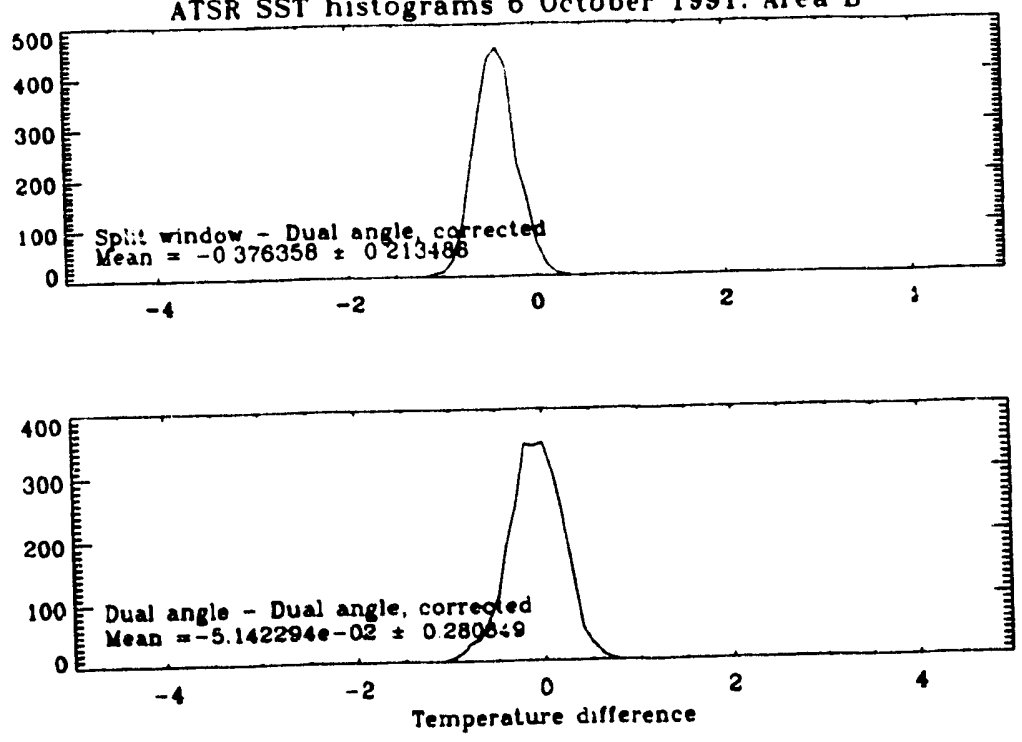

Figure 27. Histograms of the SST pixel values retrieved in the boxed area B in Figure 24. Differences are shown referred to the dual-angle SST retrieval calculated using the corrected positions of the forward view measurements. 
ATSR SST hlstograms o October 1991. Area $c$
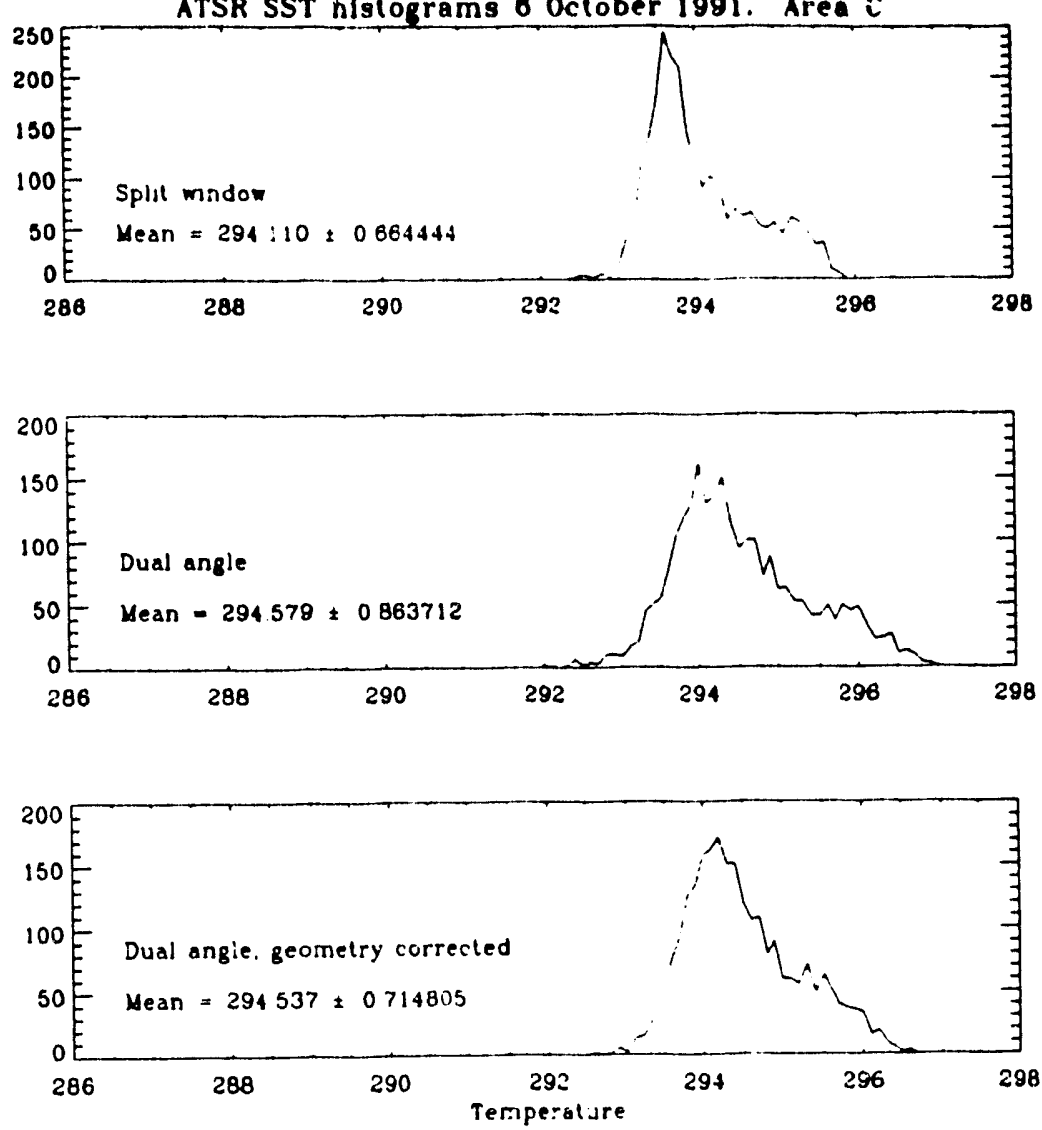

ATSR SST histograms 6 October 1991. Area
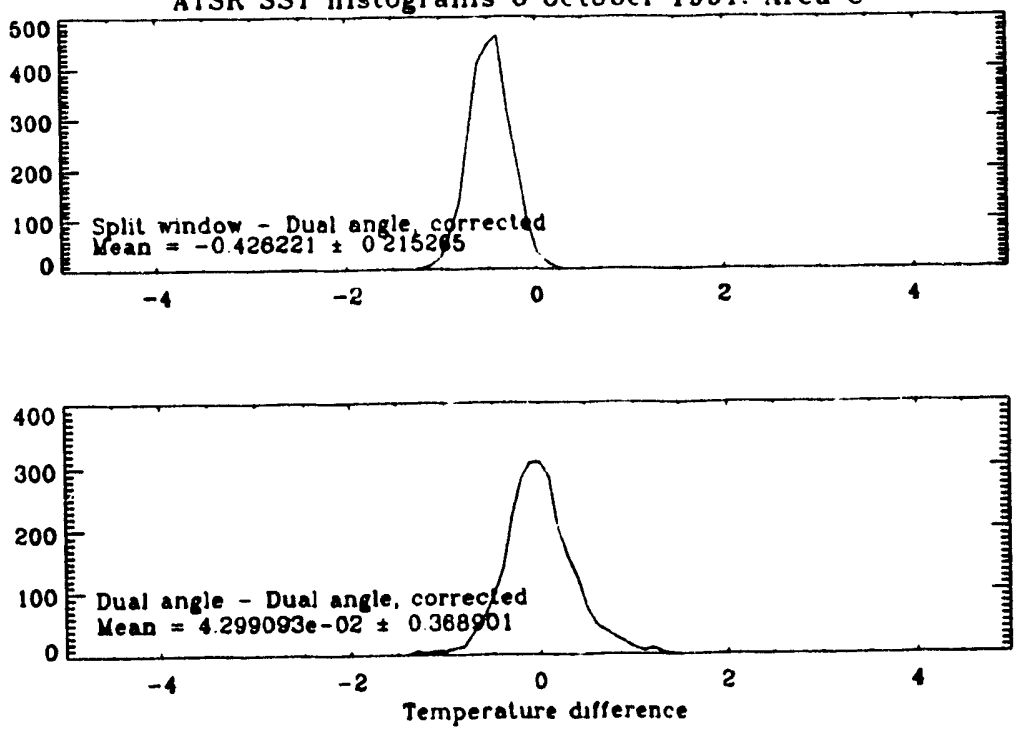

Figure 28. Histograms of the SST pixel values retrieved in the boxed area C in Figure 24. Differences are shown referred to the dual-angle SST retrieval calculated using the corrected positions of the forward view measurements. 
ATSR SST histograms 6 Octooer 1091. Area D
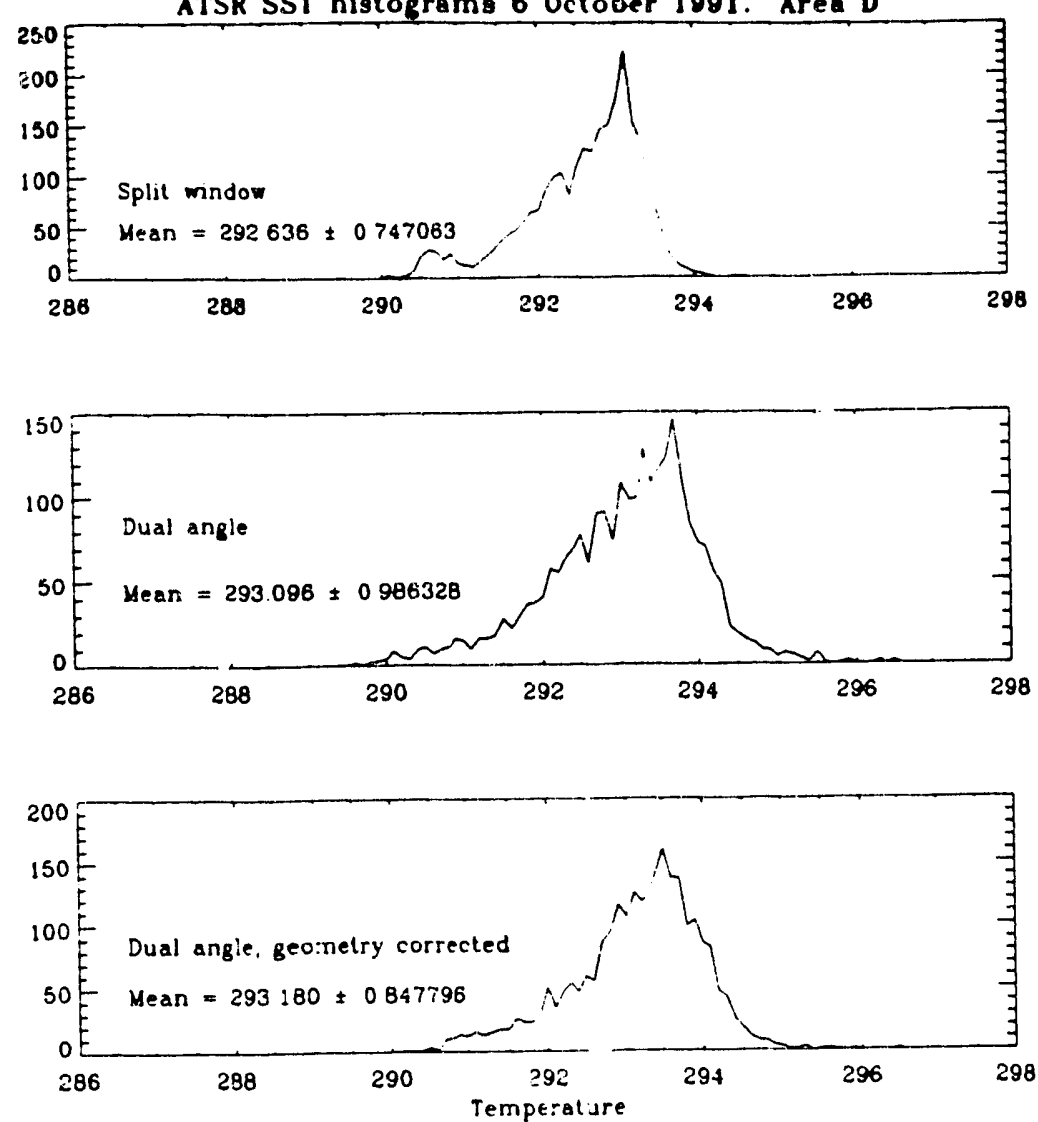

ATSR SST histograms 6 October 1991. Area D
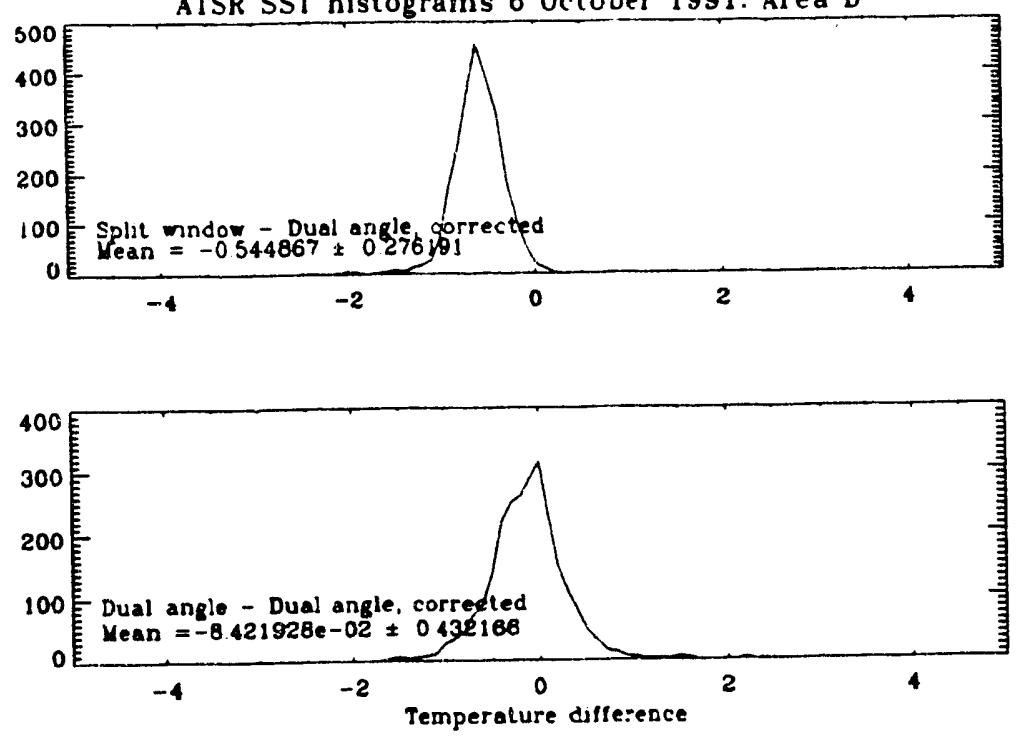

Figure 29. Histograms of the SST pixel values retrieved in the boxed area D in Figure 24. Differences are shown referred to the dual-angle SST retrieval calculated using the corrected positions of the forward view measurements. 

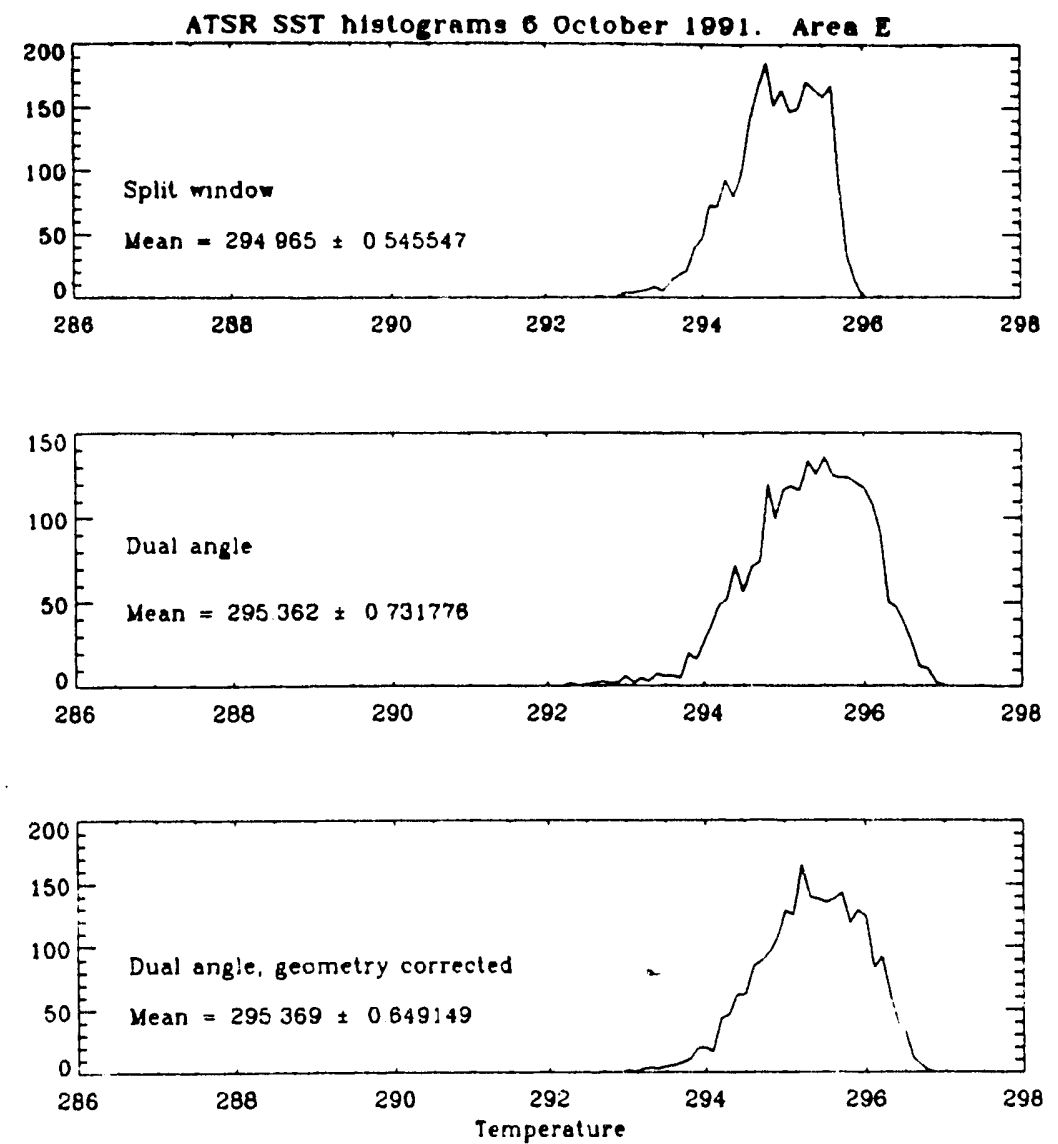

ATSR SST histograms 6 October 1991. Area E
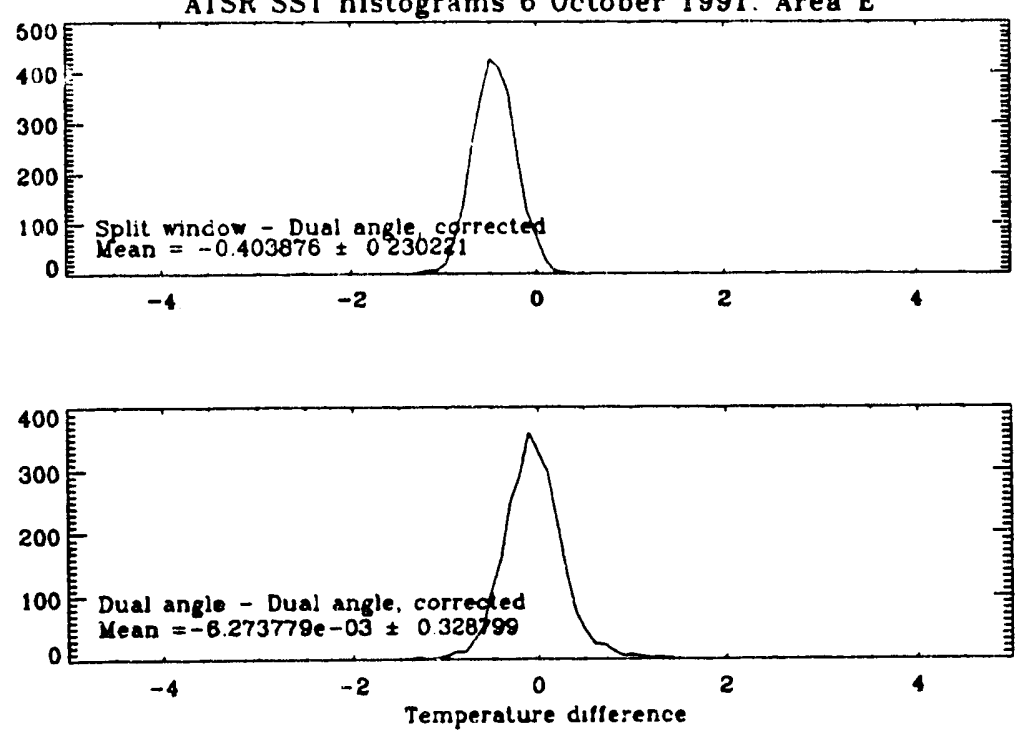

Figure 30. Histograms of the SST pixel values retrieved in the boxed area E in Figure 24. Differences are shown referred to the dual-angle SST retrieval calculated using the corrected positions of the forward view measurements. 

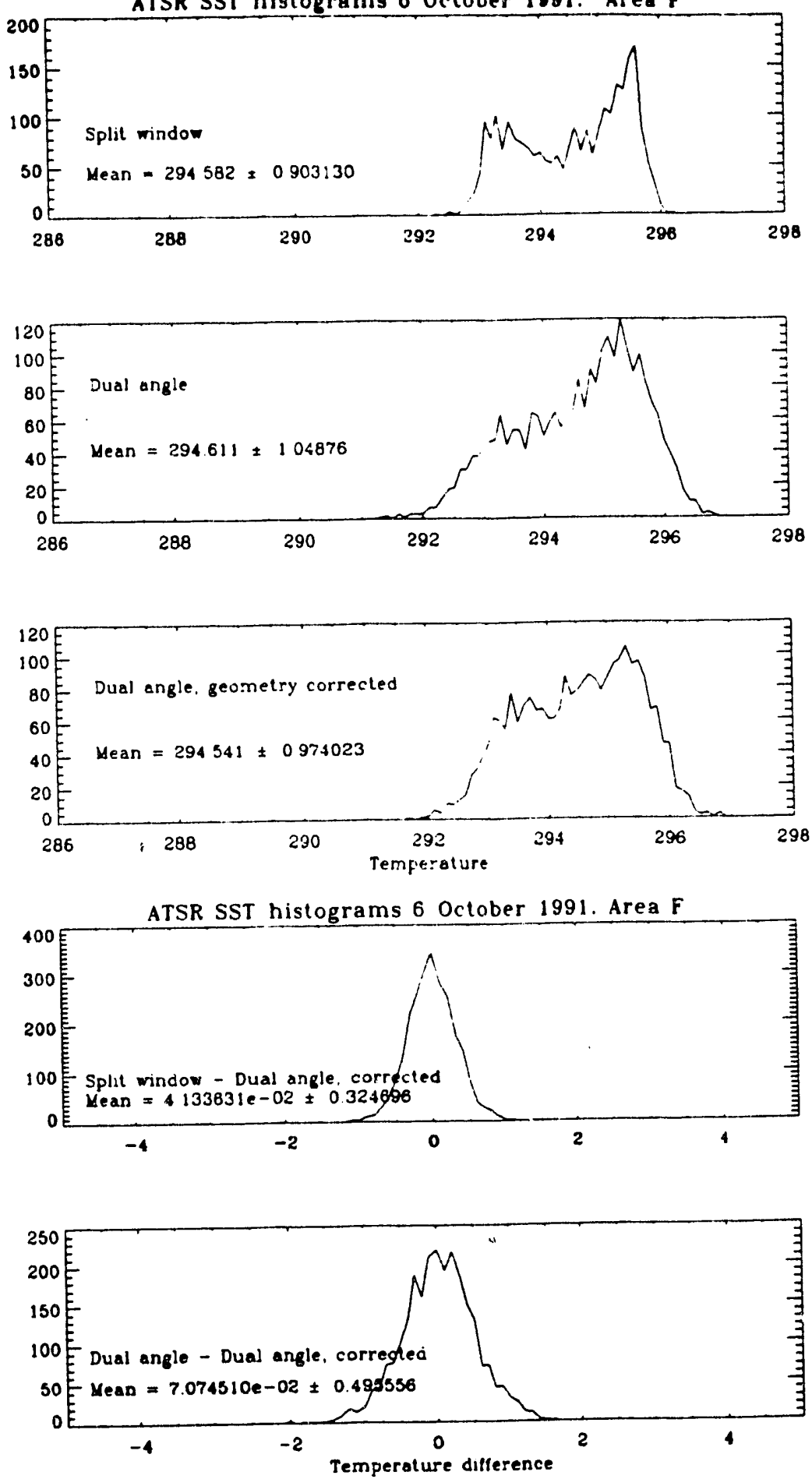

Figure 31. Histograms of the SST pixel values retrieved in the boxed area F in Figure 24. Differences are shown referred to the dual-angle SST retrieval calculated using the corrected positions of the forward view measurements. 
$\nabla$
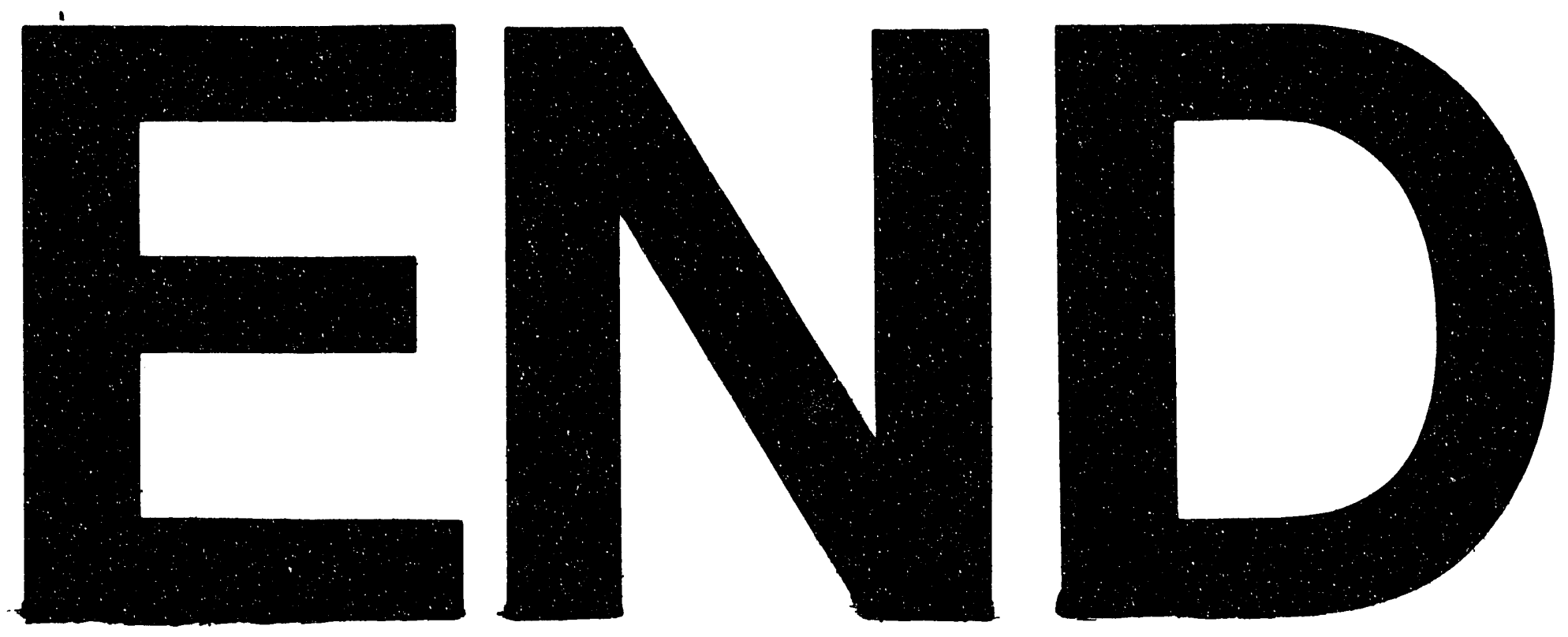

xs

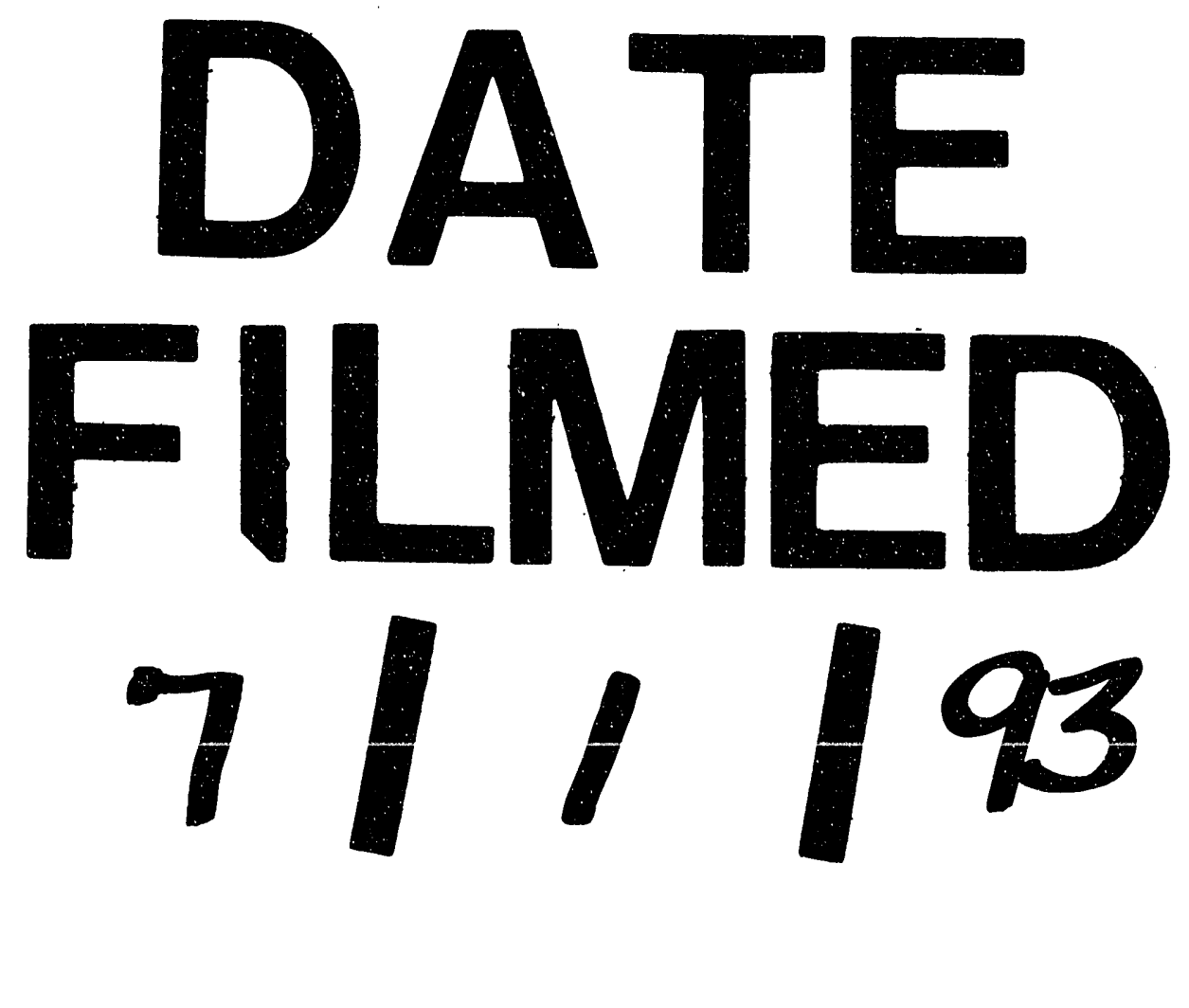


